\title{
DEUTERATED THIOFORMALDEHYDE IN THE BARNARD 1 CLOUD
}

\author{
N. Marcelino \\ IRAM, Av. Divina Pastora, 7, 18012 Granada, Spain \\ marcelino@iram.es \\ J. Cernicharo \\ DAMIR, IEM-CSIC, 28006 Madrid, Spain \\ cerni@damir.iem.csic.es \\ E. Roueff \\ LUTH (CNRS/UMR8102 and Observatoire de Paris), place J. Janssen, 92195 Meudon \\ cedex France \\ Evelyne.Roueff@obspm.fr \\ M. Gerin \\ LERMA (CNRS/UMR8112 - Observatoire de Paris and Ecole Normale Superieure), 24 \\ Rue Lhomond, 75231 Paris cedex 05, France \\ gerin@lra.ens.fr \\ and \\ R. Mauersberger \\ IRAM, Av. Divina Pastora, 7, 18012 Granada, Spain \\ mauers@iram.es
}

\begin{abstract}
We present observations of the singly and doubly deuterated species of thioformaldehyde, HDCS and $\mathrm{D}_{2} \mathrm{CS}$, towards the dark cloud Barnard 1. This is the first detection of $\mathrm{D}_{2} \mathrm{CS}$ in Space and in dense and cold prestellar regions. Column densities obtained using rotational diagrams and a Large Velocity Gradient
\end{abstract}


model show an extremely high D-enhancement in thioformaldehyde in Barnard 1. Although the column density of $\mathrm{H}_{2} \mathrm{CS}$ is smaller than that of $\mathrm{H}_{2} \mathrm{CO}$, both species show similar D-enhancements in their singly and doubly deuterated species. A chemical model -including multiply deuterated species- has been used in order to interpret the observations.

Predicted rotational frequencies from laboratory data for HDCS and $\mathrm{D}_{2} \mathrm{CS}$ are significantly in error when compared to the observed frequencies in Space. Consequently, we have derived new rotational constants for these two species and for $\mathrm{H}_{2} \mathrm{CS}$ and $\mathrm{H}_{2} \mathrm{C}^{34} \mathrm{~S}$ using the observed frequencies in Barnard 1. The new rotational constants allow to predict the rotational transitions of these species with the accuracy needed for the narrow line emerging from dark clouds. Rotational constants for HDCS and $\mathrm{D}_{2} \mathrm{CS}$ have been obtained from the observed transitions in the laboratory and in Space.

Subject headings: ISM: abundances — ISM: individual objects: (Barnard 1) — ISM: molecules

\section{INTRODUCTION}

For a long time, singly deuterated interstellar molecules are known to be present in cold molecular clouds with an extremely high abundance enhancement due to chemical fractionation (van Dishoeck et al. 1995; Minowa et al. 1997; Saito et al. 2000; Tiné et al. 2000; Turner 2001; Parise et al. 2002). The formation of deuterated molecules is preferred at low temperatures $(\leq 80 \mathrm{~K})$ and leads to a high degree of fractionation in cold and dense dark clouds without embedded luminous sources. These prestellar cores offer the opportunity to study the cold and dense evolutionary stage in which the deuteration of molecules supposedly occurred. Although this is a relatively well understood chemical process, the observation in the last few years of multiply deuterated molecules has renewed interest in deuterium fractionation in dense clouds : $\mathrm{ND}_{2} \mathrm{H}$ (Roueff et al. 2000); $\mathrm{ND}_{2} \mathrm{H}$ and $\mathrm{D}_{2} \mathrm{CO}$ (Loinard et al. 2001); $\mathrm{ND}_{3}$ (Lis et al. 2002); $\mathrm{D}_{2} \mathrm{~S}$ (Vastel et al. 2003); $\mathrm{D}_{2} \mathrm{CO}$ (Ceccarelli et al. 2002; Bacmann et al. 2003); $\mathrm{CHD}_{2} \mathrm{OH}$ and $\mathrm{CD}_{3} \mathrm{OH}$ (Parise et al. 2002, 2004). Among these deuterium isotopic species, there are, so far, only three sulfur bearing deuterated molecules, HDS and $\mathrm{D}_{2} \mathrm{~S}$, detected towards several protostars and dense cores (Vastel et al. 2003; van Dishoeck et al. 1995); and HDCS, which has been detected toward TMC-1 (Minowa et al. 1997).

Our new data and, in particular the high enhancement in the fractionation of multiply deuterated species, are requiring a review of chemical models. The presence of deuterated molecular species in star forming regions like Orion-IRc2 and IRAS 16293-2422 (Turner 
1990; van Dishoeck et al. 1995; Ceccarelli et al. 1998; Loinard et al. 2000) has been taken as signs for an active grain surface chemistry followed by desorption when the physical processes associated to recent star formation activity increases the temperature of the gas and of dust grains. However, this is not the case for dark clouds, where the kinetic temperature is too low for efficient evaporation of ice grain mantles. Roberts \& Millar (2000) found that gas phase chemistry can account for the large abundances of both singly and doubly deuterated molecules when the gas is very depleted of molecules and atoms. The reason is that both $\mathrm{CO}$ and $\mathrm{O}$ efficiently destroy $\mathrm{H}_{3}^{+}$. Hence when $\mathrm{CO}$ and $\mathrm{O}$ are sufficiently depleted, $\mathrm{H}_{3}^{+}$is converted efficiently into $\mathrm{H}_{2} \mathrm{D}^{+}$in the reaction with $\mathrm{HD}$. Subsequent reactions of $\mathrm{H}_{2} \mathrm{D}^{+}$with HD leads to $\mathrm{D}_{2} \mathrm{H}^{+}$and finally to the formation of $\mathrm{D}_{3}^{+}$. These ions propagate the deuterium to other molecules (Lis et al. 2002; Roberts et al. 2003). In their model, Roberts et al. (2003), conclude that in regions where $\mathrm{CO}$ is higly depleted, the abundance of $\mathrm{D}_{2} \mathrm{H}^{+}$will be simillar than that of $\mathrm{H}_{2} \mathrm{D}^{+}$and that $\mathrm{D}_{3}^{+}$could be the most abundant form of deuterated $\mathrm{H}_{3}^{+}$. The first prediction has been confirmed recently with the detection of $\mathrm{D}_{2} \mathrm{H}^{+}$toward the prestellar core 16293E (Vastel et al. 2004). For an early evolution time $\left(\sim 2-4 \times 10^{4}\right.$ yr $)$ the double and triple deuterated species could have large enhancements (Roberts et al. 2003). In the case of Barnard 1, Lis et al. (2002), based on their $\mathrm{C}^{18} \mathrm{O}$ and $\mathrm{C}^{17} \mathrm{O}(2-1)$ observations found that $\mathrm{C}^{18} \mathrm{O} / \mathrm{H}_{2}=5.4 \times 10^{-8}$, which is $\sim 3$ times lower than the canonical value, $\mathrm{C}^{18} \mathrm{O} / \mathrm{H}_{2}=1.7 \times 10^{-7}$ (Frerking et al. 1982; Cernicharo \& Guélin 1987), indicating that an appreciable amount of $\mathrm{CO}$ is depleted onto grains. Modelling with low temperature conditions and high depletion factors allows a satisfactory comparison with the observations of doubly and triply deuterated ammonia -see e.g. $\mathrm{NHD}_{2}$ towards L134N (Roueff et al. 2000)- and also helps to explain the high abundances observed in star forming regions in terms of grain chemistry models. The recent detection of doubly deuterated $\mathrm{H}_{2} \mathrm{~S}$ provides a stimulating impetus to consider other sulfur molecules and extend the previously elaborated chemical schemes.

During a 3mm line survey on dark clouds (Barnard 1, TMC-1, L1544, L183 -Marcelino et al., in prep.), we found several transitions that initially were considered as unidentified. Taking into account the reduced number of possible candidates, the fact that the lines were strongest in Barnard 1 (see Figure 1), and the strong deuterium enhancement found in these sources by several authors (see, e.g., Roueff et al. 2000; Gerin et al. 2001, and references therein), we concluded that these lines were arising from $\mathrm{D}_{2} \mathrm{CS}$ and HDCS. While single deuterated thioformaldehyde had been detected at lower frequencies in TMC-1 (Minowa et al. 1997); this is now the first detection of $\mathrm{D}_{2} \mathrm{CS}$ in Space. Once the carriers were identified, and given the extremely large deuterium enhacement indicated by the observations, we concentrated our efforts and available observing time in the source showing the strongest lines, i.e., Barnard 1. In Section 2 we present the observing procedures and in Section 3 the main results. In this section we discuss the rotational constants of thioformaldehyde and its 
isotopomers. We also analyze the physical and chemical conditions of Barnard 1 and derive the column densities for the different thioformaldehyde isotopic species. Section 4 is devoted to the discussion and to the chemical analysis of the results.

\section{OBSERVATIONS}

The observations were carried out using the IRAM 30-m radio telescope at Pico Veleta (near Granada, Spain) between 2003 October and 2004 February. Spectral lines arising from singly and doubly deuterated thioformaldehyde between 83 and $155 \mathrm{GHz}$ were observed in October. In January we performed most of the observations for the main isotopic species. Up to four SIS receivers were used simultaneously. Each receiver was tuned to single side band with image rejections within 20-27 dB (3mm receivers), 12-16 dB (2mm receivers) and $13 \mathrm{~dB}$ (1mm receivers). System temperatures were 100-225 K in October for the 3 and $2 \mathrm{~mm}$ receivers with atmospheric opacities between 0.05-0.1. In 2004 January weather conditions were even better allowing excellent observations at $1 \mathrm{~mm}$. During this run we obtained temperatures below $100 \mathrm{~K}$ at $3 \mathrm{~mm}$ and below $200 \mathrm{~K}$ at $1 \mathrm{~mm}$ (atmospheric opacities at 225 $\mathrm{GHz}$ were below 0.1 ).

Calibration was performed using two absorbers at different temperatures and the ATM code developed by Cernicharo (1985) and recently updated by Pardo et al. (2001). An autocorrelator providing several backends with $40 \mathrm{kHz}$ and $80 \mathrm{kHz}$ of resolution was used. The velocity resolution was between $0.08-0.23 \mathrm{kms}^{-1}$ depending on the frequency. Telescope pointing and focus were checked every 1 and 3 hours respectively on strong and nearby continuum sources. The largest pointing error between consecutive pointing scans never exceeded 3".

Most of the observations were performed using wobbler and frequency switching techniques, using for the latter a frequency throw of $7.2 \mathrm{MHz}$-which eliminates the main ripple

component coming from the telescope- and in some cases we used position switching. The throw for wobbler and position switching was 240" and 10' respectively, both in azimut. Taking into account the size of the source, these offsets are enough to provide a clean reference. On-source integration times were typically $\sim 1-2 \mathrm{~h}$, resulting in rms main beam antenna temperatures between 15-50 mK. Observed line parameters obtained from Gaussian fits to the observed lines are given in Table 1 and the line profiles are shown in Fig. 2-4. Line intensities for the observed transitions are given in main beam brightness temperature scale. The main beam telescope efficiencies are $0.78-0.75,0.69$ and 0.57 at 3,2 and $1 \mathrm{~mm}$ respectively.

In order to compare the deuterium enhancement in thioformaldehyde with that of 
formaldehyde we also observed several rotational transitions of $\mathrm{H}_{2} \mathrm{CO}, \mathrm{HDCO}, \mathrm{D}_{2} \mathrm{CO}$ and $\mathrm{H}_{2}^{13} \mathrm{CO}$ in 2004 February. The observed line parameters are given in Table 2 and the corresponding line profiles are shown in Figure 5.

\section{RESULTS}

Figure 2a shows the observed lines for the singly and doubly deuterated species of thioformaldehyde. The fact that the same transitions of both molecules appear at different velocities when assuming the predicted frequencies from available line frequency catalogs -see, e.g., JPL (Pickett et al. 1998); Köln (Müller et al. 2001); Lovas (Lovas 1992) and Cernicharo (Cernicharo et al. 2000)- indicates a considerable error in the frequencies used. We have used the new frequencies for these species derived from our observations to improve the molecular constants and to obtain better values for line prediction at higher frequencies (see Section 3.1). Figure $2 \mathrm{~b}$ shows that the agreement between HDCS and $\mathrm{D}_{2} \mathrm{CS}$ line profiles is excellent when the new predicted frequencies for both species are used.

In Figure 2 we can see that lines arising from HDCS are moderately stronger than those from $\mathrm{D}_{2} \mathrm{CS}$, which, although indicating a large column density for the singly deuterated species also implies a very high D-enhancement for $\mathrm{D}_{2} \mathrm{CS}$ (see below). Line widths are rather narrow as indicated in Table 1. The similarity between line profiles from both species indicates that they coexist spatially.

We observe a double peak profile for $\mathrm{H}_{2} \mathrm{CO}$ lines probably due to selfabsorption by foreground gas (the high velocity gas associated with IRAS 03301+3057, a young stellar object which is close to the strong ammonia peak, could also, perhaps, affect the line profile of formaldehyde; we have checked that the absorption feature is not coming from emission in the off position by checking the spectra in frequency switching mode). Lines from the deuterated species of $\mathrm{H}_{2} \mathrm{CO}$ and from $\mathrm{H}_{2}{ }^{13} \mathrm{CO}$ are wider than the lines arising from thioformaldehyde and its isotopomers, but less than those of $\mathrm{H}_{2} \mathrm{CO}$ and they do not show the line wings observed in formaldehyde. Lines arising from $\mathrm{H}_{2} \mathrm{CO}$ are stronger than those from $\mathrm{H}_{2} \mathrm{CS}$ and lines from $\mathrm{HDCO}$ and $\mathrm{D}_{2} \mathrm{CO}$ are about two times stronger than the lines arising from deuterated thioformaldehyde, indicating a higher column density for the different $\mathrm{H}_{2} \mathrm{CO}$ isotopic species.

\subsection{Molecular Line Frequencies}

In order to have a coherent picture of the line profile from the different transitions

of thioformaldehyde and its isotopes we performed a determination of the velocity of the 
source as a mandatory step in deriving line frequencies. We used 19 molecular lines that were observed in Barnard 1 during the present work, and for which laboratory frequencies or confident frequency predictions are available (JPL, Köln, Lovas, and/or Cernicharo catalogs; see above). The lines showing some evidences of opacity effects were discarded. Finally, only lines from $\mathrm{CCH}$ (some hyperfine components), methanol, deuterated formaldehyde, CCS, and one of the hyperfine components of the $N=1-0$ transition of $\mathrm{CN}$ were used. The averaged velocity obtained from these lines is $6.70 \pm 0.05 \mathrm{~km} \mathrm{~s}^{-1}$, where the error translates the uncertainty from laboratory measurements and also the presence of a second velocity component in the cloud at $7.5 \mathrm{~km} \mathrm{~s}^{-1}$ that reduces the accuracy of the Gaussian fits. The estimated LSR velocity of $6.70 \mathrm{~km} \mathrm{~s}^{-1}$ was assumed for all lines in Table 1 when deriving observed frequencies.

We have observed four HDCS transitions, based on the frequencies calculated from the rotational constants of Minowa et al. (1997) and seven from $\mathrm{D}_{2}$ CS based on the frequencies derived from the rotational constants of Cox et al. (1982). The rotational constants for the latter species have been derived from high $J$ transitions. However, the largest frequency covered by the laboratory data is $35 \mathrm{GHz}$, hence, one could expect significant uncertainties for rotational transitions at large frequencies. A comparison of the line profiles of HDCS and $\mathrm{D}_{2} \mathrm{CS}$ (Fig. 2) suggests frequency errors in the latter species as large as 0.1-0.2 MHz. Even for HDCS for which the rotational constants have been derived from a significant set of data (Minowa et al. 1997), observed frequencies in dark clouds are often different from those obtained in the laboratory. As an example, the $3_{03}-2_{02}$ line of HDCS has been observed by Minowa et al. (1997) with a laboratory frequency of $92981.601 \pm 0.018 \mathrm{MHz}$, while the same authors reported a frequency for this line from observations of TMC-1 of $92981.680 \mathrm{MHz}$. We have observed the same line in Barnard 1 with much better signal to noise ratio and we obtain (see Table 1) a frequency of $92981.658 \pm 0.030 \mathrm{MHz}$. Consequently, the use of the laboratory frequency will produce a $0.17 \mathrm{~km} \mathrm{~s}^{-1}$ velocity shift in the line -see Figure 2 . It seems evident that the calculated frequencies in the available line catalogs have significant errors for some molecules. This is a critical point, because astronomers often compare line profiles from different isotopomers of a given molecular species to trace cloud collapse or line opacities. Uncertainties in computed frequencies larger than $20 \mathrm{kHz}$ will produce significant velocity shifts when comparing different lines from the same species or from different molecules.

The situation is even worse for rare isotopic substitutions like deuterium, ${ }^{34} \mathrm{~S}$ or ${ }^{13} \mathrm{C}$. The rare isotopomer $\mathrm{H}_{2} \mathrm{C}^{34} \mathrm{~S}$ is a much better tracer of the column density of thioformaldehyde than the lines from the main isotope. We observed several lines of this species (see Table 1) using frequencies from the JPL line catalog. The number of measured laboratory frequencies for this species is small and, hence, computed frequencies have considerable uncertainties. For example the $3_{03}-2_{02}$ line predicted at $101283.899 \mathrm{MHz}$ was observed at $101284.331 \mathrm{MHz}$, 
the $3_{12}-2_{11}$ line predicted at $102810.609 \mathrm{MHz}$ was observed at $102807.426 \mathrm{MHz}$, the $4_{14}-3_{13}$ predicted at $133031.473 \mathrm{MHz}$ was observed at $133027.035 \mathrm{MHz}$, and the $4_{13}-3_{12}$ line predicted at $137077.543 \mathrm{MHz}$ was observed at $137071.099 \mathrm{MHz}$. That the observed frequencies were corresponding to the searched lines of $\mathrm{H}_{2} \mathrm{C}^{34} \mathrm{~S}$ was confirmed by a simultaneous fit (see below) to the laboratory and space frequencies of a few rotational constants (several of them fixed to the values of the main isotope -note that $\mathrm{H}_{2} \mathrm{CS}$ and $\mathrm{H}_{2} \mathrm{C}^{34} \mathrm{~S}$ have the same inertia moment around the $\mathrm{A}$ axis of the molecule). The large differences that are found between space spectroscopy and predicted frequencies could prompt for negative results and/or to reach a confuse situation as we often look the on-line frequency catalogs as a final product ready to be used. Special care has to be taken when using frequencies predicted from a fit to a reduced number of observed lines, or for predictions in frequency domains outside those observed in the laboratories.

Using the astronomically measured frequencies given in Table 1 and those observed in the laboratories we performed fits to the rotational constants of $\mathrm{H}_{2} \mathrm{CS}, \mathrm{H}_{2} \mathrm{C}^{34} \mathrm{~S}, \mathrm{D}_{2} \mathrm{CS}$ and HDCS. The results are given in Tables 3 to 6 . These tables also give the fits obtained from the laboratory data alone. Although HDCS is a nearly prolate symmetric top and a S-reduced Hamiltonian should be preferred (Gordy \& Cook 1984; Watson 1977; Minowa et al. 1997), we adopted the asymmetric (A) reduced form of the Watson Hamiltonian in a $\mathrm{I}^{r}$ representation (Watson 1967, 1977). Laboratory frequencies for the different isotopic species have been taken from Clouthier \& Ramsay (1983), Dangoise et al. (1978), Chu et al. (1973), Cox et al. (1982) and McNaughton \& Bruget (1993). Although it seems that the rotational constants in Tables 3-6 show little variation between those obtained from laboratory data and those derived from laboratory plus space observations, these variations account for changes in the predicted frequencies of 0.1-0.2 MHz between both sets of data. The species the less affected by the introduction of the space frequencies is HDCS and the most $\mathrm{H}_{2} \mathrm{C}^{34} \mathrm{~S}$.

One could think that the situation should be better for the main isotope of thioformaldehyde for which 60 of its rotational lines have been measured in the laboratory. However, Figure 3 shows that the laboratory frequencies and the calculated ones result in different velocities for the lines. Although, the uncertainties in the laboratory measurements are large, we could expect that the global fit to all laboratory data will produce rotational constants accurate enough to allow a good estimate of the spectrum of $\mathrm{H}_{2} \mathrm{CS}$. As can be seen in the central panels of Figure 3 this is really the case, but these predictions are not accurate enough for the narrow lines emerging from dark clouds. Hence, the frequencies of the eight observed lines of $\mathrm{H}_{2} \mathrm{CS}$ were obtained following a similar procedure to that adopted for its rare isotopes and a new set of rotational constants was obtained. The results are given in Table 3. With the new set of rotational constants for the four isotopomers of thioformaldehyde, we 
have computed their frequencies and those corresponding to the observed lines are given in Table 1.

The observed lines of $\mathrm{H}_{2} \mathrm{CO}$ show an asymmetric profile with a red line wing which could arise from molecular outflows (see below). For $\mathrm{H}_{2} \mathrm{CO}$, HDCO and also HDCS, the observed lines present a second peak at $\sim 7.5 \mathrm{~km} \mathrm{~s}^{-1}$. This velocity component is also observed in $\mathrm{HC}^{17} \mathrm{O}^{+}, \mathrm{CCH}, \mathrm{c}_{-} \mathrm{C}_{3} \mathrm{H}$ and $\mathrm{HC}_{3} \mathrm{~N}$. Bachiller \& Cernicharo (1984) already found, based on the asymmetric and wide ${ }^{13} \mathrm{CO}$ line profiles, two velocity components in the cloud (at 6.5 and $7.2 \mathrm{~km} \mathrm{~s}^{-1}$ ). The lines of $\mathrm{D}_{2} \mathrm{CO}$ peak at $6.7 \mathrm{~km} \mathrm{~s}^{-1}$ (see Figure 5), while those of HDCO and $\mathrm{H}_{2}^{13} \mathrm{CO}$ have their emission maxima at slightly lower velocities. If we assume for these lines a cloud velocity of $6.7 \mathrm{kms}^{-1}$, then the frequencies for the lines of these two isotopes of $\mathrm{H}_{2} \mathrm{CO}$ will be $0.1 \mathrm{MHz}$ above of the predicted ones, which are much more accurate (large number of measured lines in the laboratory) than those of the isotopes of $\mathrm{H}_{2} \mathrm{CS}$. Hence the observed velocities for $\mathrm{HDCO}$ and $\mathrm{H}_{2}^{13} \mathrm{CO}$ could correspond to optical depth effects or to chemical cloud structure. In fact, the high intensity of the HDCO lines and the asymmetric profiles in $\mathrm{H}_{2} \mathrm{CO}$ indicate high optical depths in the Barnard 1 core, or high foreground column densities, in the rotational lines of this species, even in those of HDCO.

\subsection{Column Densities and Physical Conditions}

\subsubsection{Previous Studies of Barnard 1}

Barnard 1 is one of the highest column density molecular sources in the Perseus complex with recent low-mass star formation activity, as indicated by several young stellar objects three of them without optical counterpart- detected by IRAS. Bachiller \& Cernicharo (1984) made the first study of this region using visual extinction maps derived from star counts (see Cernicharo et al. 1984), and emission maps of $\mathrm{CO}$ and its isotopomers, $\mathrm{HCO}^{+}, \mathrm{H}^{13} \mathrm{CO}^{+}$ and $\mathrm{NH}_{3}$. From star counts, they found Barnard 1 to be composed of two condensations of $\mathrm{A}_{v} \geq 5 \mathrm{mag}$. They modeled the cloud in four regions -core, internal and external envelope and halo- of different size and physical conditions depending on the line intensities of the observed molecules (see also Cernicharo \& Guélin 1987). The innermost layer, i.e. the core, was studied from ammonia data. With a visual extinction $\sim 10$ and a size of $0.5 \mathrm{pc}$ (at $200 \mathrm{pc}$ of distance), the average density in the core ranges from $10^{3}$ to $3 \times 10^{4} \mathrm{~cm}^{-3}$ and the kinetic temperature is $12 \pm 2 \mathrm{~K}$ (in concordance with $\mathrm{CO}$ data). $\mathrm{H}^{13} \mathrm{CO}^{+}$and $\mathrm{HCO}^{+}$ emission is also detected in this region with column densities $\mathrm{N}\left(\mathrm{H}^{13} \mathrm{CO}^{+}\right) \sim 2 \times 10^{12} \mathrm{~cm}^{-2}$ and $\mathrm{N}\left(\mathrm{HCO}^{+}\right) \sim 2 \times 10^{14} \mathrm{~cm}^{-2}$, where the last one extends to the internal envelope. The rest of the cloud can be characterised by different isotopomers of CO. The density of the internal envelope was obtained from $\mathrm{C}^{18} \mathrm{O}$ emission and results to be $2 \times 10^{3} \mathrm{~cm}^{-3}$. This region is 
very extended $(\sim 1 \mathrm{pc})$ and contains the young stellar objects and the $\mathrm{NH}_{3}$ globule. The visual extinction here is $\sim 3-4 \mathrm{mag}$. The external envelope, with a density below $10^{3} \mathrm{~cm}^{-3}$ and $\mathrm{A}_{v} \sim 2-3 \mathrm{mag}$, was studied from ${ }^{13} \mathrm{CO}$ emission. The halo $\left(\mathrm{A}_{v} \sim 1-2 \mathrm{mag}\right)$ is the most external zone with a large spatial size and traced by moderate/weak $\mathrm{CO}$ emission -see also Cernicharo \& Guélin (1987). They also made a dynamical study of the cloud and concluded that it is being supported by magnetic fields and/or turbulence.

Bachiller et al. (1990) mapped Barnard 1 in several molecules with higher angular resolution, resolving some spatial structures in the main dense core from observations of $\mathrm{NH}_{3}$. In this region they found density values of $7 \times 10^{4} \mathrm{~cm}^{-3}$ in the southern clump, and $>3.7 \times 10^{4} \mathrm{~cm}^{-3}$ in the northern one. They studied the external and the internal envelopes from ${ }^{13} \mathrm{CO}, \mathrm{C}^{18} \mathrm{O}$ and $\mathrm{CS}$ emission. CS maps show the dense region to have a size of $\sim 2$ $\mathrm{pc} \times 5 \mathrm{pc}$ (at $350 \mathrm{pc}$ of distance). The strongest emission of this molecule is restricted to the internal envelope, but extends to the external one with lower intensities, probably due to the existence of several dense clumps. They obtained $n\left(\mathrm{H}_{2}\right)>2 \times 10^{3}$ and $10^{3} \mathrm{~cm}^{-3}$ for the internal and the external envelopes, respectively. The kinetic temperature is $11-14 \mathrm{~K}$ in the densest regions and increases to $\mathrm{T}_{\text {kin }}>20 \mathrm{~K}$ at the edge of the cloud, showing that the cloud is submitted to some heating from the exterior.

Continuum observations indicate the presence of four clumps in Barnard 1 (see Matthews \& Wilson 2002). Among them, B1-b corresponds to the position we are observing and the source IRAS03301+3057 is close to B1-a. Barnard1-b has two intense (sub)millimeter continuum sources, probably Class 0 sources associated to compact protostellar objects (Hirano et al. 1999). However, no outflows have been detected from these objects. Based on their dust continuum observations, Hirano et al. (1999) obtained a $\mathrm{H}_{2}$ column density $\sim 1.3 \times 10^{23}$ $\mathrm{cm}^{-2}$ in a $15^{\prime \prime}$ beam. Assuming a distance of $200 \mathrm{pc}$, this column density corresponds to a mean gas density of $2.9 \times 10^{6} \mathrm{~cm}^{-3}$ in the beam diameter, showing that high gas densities are present in the source. From CO $J=2-1$ observations, Bachiller et al. (1990) found a high velocity flow emerging from IRAS $03301+3057$, a young stellar object located near the strong ammonia peak (B1-a). This outflow, which covers a region of about 40", was studied in detail by Hirano et al. (1997) from CO $(J=1-0)$ emission and by Yamamoto et al. (1992) from $\mathrm{SiO} J=2-1$ and $J=1-0$ lines. The interaction of the flow with the ambient gas is traced by the different Herbig-Haro objects present in this cloud (Yan et al. 1998).

The wings in the $\mathrm{H}_{2} \mathrm{CO}$ lines shown in Figure 5 could be produced by the high velocity gas associated to IRAS $03301+3057$ (located in B1-a). Note, however, that our position (the B1-b clump) is about 1' East from this source, and from the compact $\mathrm{SiO}$ peak which marks the place were the outflow interacts with the cloud material. Hence, the wings could be unrelated to the deuterium source. 


\subsubsection{Molecular Background}

Formaldehyde and thioformaldehyde have both a nuclear spin statistics that separates the rotational levels into two different sets. Radiative and collisional transitions between ortho and para species are strictly forbidden, hence, these two species behave like two different molecules. Rotational levels with $\mathrm{k}_{-1}$ and $\mathrm{k}_{+1}$ values even/odd or even/even belong to the para species while those with odd/even and odd/odd belong to the ortho species. For $\mathrm{H}_{2} \mathrm{CO}, \mathrm{H}_{2} \mathrm{CS}$, and their ${ }^{13} \mathrm{C}$ isotopic species the nuclear spin statistics leads to a $3: 1$ value for the ortho/para ratio. The singly deuterated species HDCO and HDCS do not have this separation on the rotational levels because the symmetry of the molecule has been broken by the deuteration. However, these species have b-type rotational transitions as deuteration introduces a weak permanent dipole moment along the $\mathrm{B}$ axis of the molecule (typically 0.2-0.3 D). Doubly deuterated species on the other hand also have a symmetry axis, and the nuclear spin statistics separate the rotational levels. However, as the nuclear spins are different, rotational levels of doubly deuterated isotopic species with $\mathrm{k}_{-1}$ and $\mathrm{k}_{+1}$ values odd/even or odd/odd belong to the para species, and those with even/odd even/even to the ortho one, i.e., just the opposite than for the main isotopic species. Moreover, the ortho/para ratio in the doubly deuterated species of formaldehyde and thioformaldehyde is 2 .

\subsubsection{Thioformaldehyde}

In order to derive column densities for thioformaldehyde and their isotopes we have proceeded in two different ways. The first method we have used consists in the analysis of rotational diagrams for the observed isotopes of thioformaldehyde, see, e.g., Goldsmith \& Langer (1999). From these diagrams one can obtain the molecular column density and the excitation temperature of the molecular rotational levels (assuming all levels are populated by a single excitation temperature). From these diagrams we obtain common rotational temperatures close to $10 \mathrm{~K}, T_{\text {rot }}=9.5 \pm 1.0,10.2 \pm 2.0$, and $7.4 \pm 0.8 \mathrm{~K}$ for HDCS, $\mathrm{D}_{2} \mathrm{CS}$ and $\mathrm{H}_{2} \mathrm{CS}$ respectively, which suggests that the molecular hydrogen volume density is large enough to thermalize the rotational levels of these molecules (in the case of thermalization, $T_{\text {rot }}$ should be close to $T_{\text {kin }}$ ). The derived column densities for these species, assuming that the emitting source fills the beam of the 30-m radio telescope, are $\mathrm{N}\left(\mathrm{H}_{2} \mathrm{CS}\right)=1.2-2.0 \times 10^{13} \mathrm{~cm}^{-2}, \mathrm{~N}(\mathrm{HDCS})=4.5-7.0 \times 10^{12} \mathrm{~cm}^{-2}, \mathrm{~N}\left(\mathrm{D}_{2} \mathrm{CS}\right)=1.0-4.0 \times 10^{12} \mathrm{~cm}^{-2}$. Hence, the abundance ratios are $\mathrm{N}\left(\mathrm{H}_{2} \mathrm{CS}\right) / \mathrm{N}(\mathrm{HDCS}) \simeq 3 \pm 1, \mathrm{~N}(\mathrm{HDCS}) / \mathrm{N}\left(\mathrm{D}_{2} \mathrm{CS}\right) \simeq 3 \pm 2$, and $\mathrm{N}\left(\mathrm{H}_{2} \mathrm{CS}\right) / \mathrm{N}\left(\mathrm{D}_{2} \mathrm{CS}\right) \simeq 9 \pm 3$. Finally, for $\mathrm{H}_{2} \mathrm{C}^{34} \mathrm{~S}$ we have assumed the rotational temperature obtained for $\mathrm{H}_{2} \mathrm{CS}$ to derive $\mathrm{N}\left(\mathrm{H}_{2} \mathrm{C}^{34} \mathrm{~S}\right)=6.0 \pm 3.0 \times 10^{11} \mathrm{~cm}^{-2}$. The column densities of $\mathrm{H}_{2} \mathrm{CS}$ and $\mathrm{H}_{2} \mathrm{C}^{34} \mathrm{~S}$ are compatible with a galactic ${ }^{32} \mathrm{~S} /{ }^{34} \mathrm{~S}$ ratio of $24.4 \pm 5.0$ (Chin et al. 1996). This 
analysis does not provide any insight on the volume density and assumes that the lines are optically thin (which seems to be correct in view of the low column density derived for $\mathrm{H}_{2} \mathrm{C}^{34} \mathrm{~S}$ ). The volume density and other physical parameters could be derived through the observed line intensities and a Large Velocity Gradient code (see, e.g., Goldreich et al. 1974) if the collisional rates are known. We have adopted for $\mathrm{H}_{2} \mathrm{CS}$ the collisional rates of formaldehyde computed by Green et al. (1978), multiplied by a factor of 2 to take into account the different effective surface and different energy of the levels of $\mathrm{H}_{2} \mathrm{CS}$ (a similar factor to that existing between the collisional rates of $\mathrm{CO}$ and of CS). Taking into account that we have observed a large number of lines of $\mathrm{H}_{2} \mathrm{CS}$, we could check that the adopted collisional cross sections produce a good fit to the observed intensities using reasonable values for the gas density and temperature. Of course, the final result has to be in good agreement with the column densities and rotational temperatures derived from the rotational diagrams. Assuming a kinetic temperature of $10 \mathrm{~K}$ (see section 3.2.1) we derive rotational temperatures for the observed transitions of thioformaldehyde between 6.5 and $9.1 \mathrm{~K}$ for volume densities of $2-4 \times 10^{5} \mathrm{~cm}^{-3}$ and a column density of ortho and para species of 1.2 and $0.5 \times 10^{13} \mathrm{~cm}^{-2}$ respectively. These values are in reasonable agreement with those derived from the rotational diagrams.

For $\mathrm{D}_{2} \mathrm{CS}$ we have also used the same collision rates as for $\mathrm{H}_{2} \mathrm{CS}$. Assuming also a kinetic temperature of $10 \mathrm{~K}$, we derive $\mathrm{n}\left(\mathrm{H}_{2}\right)=3 \times 10^{5} \mathrm{~cm}^{-3}, T_{\text {rot }} \simeq 10 \mathrm{~K}$, and $\mathrm{N}\left(\mathrm{D}_{2} \mathrm{CS}\right) \simeq 3.0 \times 10^{12}$ $\mathrm{cm}^{-2}$, with a derived value for the ortho/para ratio of $\simeq 1.7$, very close to the expected value of 2 .

For HDCS the collisional rates could be rather different from those of the main isotope. We have tried to fit the data using the collisional rates for HNCO, but it was difficult to reach a good fit to the data with reasonable values for the physical parameters (which could be expected from this crude approximation to the collisional rates of HDCS). We adopt for HDCS the values obtained above from the rotational diagrams (note that the LVG values for the other species compare very well with those obtained from the rotational diagrams).

\subsubsection{Formaldehyde}

The column density of formaldehyde and its isotopes have been derived from an LVG analysis of the observed intensities, adopting the collisional rates of Green et al. (1978). The line profile of $\mathrm{H}_{2} \mathrm{CO}$ indicates opacities larger than 1. Hence, the column density for this species has been derived from the isotope $\mathrm{H}_{2}^{13} \mathrm{CO}$ assuming an ${ }^{12} \mathrm{C} /{ }^{13} \mathrm{C}$ isotopic ratio for dark clouds of 50 (Cernicharo \& Guélin 1987; Langer et al. 1980). Assuming again a kinetic temperature of $10 \mathrm{~K}$, the observed intensities give $\mathrm{N}\left(\mathrm{H}_{2}^{13} \mathrm{CO}\right)=1.2 \pm 0.5 \times 10^{12} \mathrm{~cm}^{-2}, \mathrm{n}\left(\mathrm{H}_{2}\right)=3 \times 10^{5}$ 
$\mathrm{cm}^{-3}$. There is no indication for an ortho/para ratio different than 3 from the observational data. The column density for the doubly deuterated species is $\mathrm{N}\left(\mathrm{D}_{2} \mathrm{CO}\right)=3.0 \pm 1.5 \times 10^{12}$ $\mathrm{cm}^{-2}$. For the single deuterated species we have assumed the same rotational temperatures as for the other isotopes of formaldehyde to obtain $\mathrm{N}(\mathrm{HDCO})=7 \pm 2 \times 10^{12} \mathrm{~cm}^{-2}$. Hence, the isotopic ratios are $\mathrm{N}\left(\mathrm{H}_{2} \mathrm{CO}\right) / \mathrm{N}(\mathrm{HDCO}) \simeq 7, \mathrm{~N}\left(\mathrm{H}_{2} \mathrm{CO}\right) / \mathrm{N}\left(\mathrm{D}_{2} \mathrm{CO}\right) \simeq 13$, and $\mathrm{N}(\mathrm{HDCO}) / \mathrm{N}\left(\mathrm{D}_{2} \mathrm{CO}\right) \simeq 2.5$. While the abundance ratios of singly over doubly deuterated species for formaldehyde and thioformaldehyde are similar $(\sim 3)$, the abundance ratio between the main isotope and the singly deuterated species is twice larger in thioformaldehyde compared to formaldehyde.

\section{ABUNDANCE RATIOS, DEUTERIUM FRACTIONATION AND CHEMICAL MODELLING}

Table 7 sumarizes several studies in dark clouds and star forming regions where deuterated molecules have been found. For Barnard 1, the new ratios obtained in this work for $\mathrm{H}_{2} \mathrm{CS}$ and $\mathrm{H}_{2} \mathrm{CO}$ are also shown. Comparing with other deuterated species detected towards this core, we can see that the D-enhancement of thioformaldehyde is among the highest values. In general the abundance ratios in Barnard 1 are only comparable with those found in the class 0 binary protostar IRAS 16293-2422. That means that deuteration processes should be similar in both sources and different than in dark and quiescent clouds.

We have extended our chemical network dedicated to deuterium containing molecules (Lis et al. 2002, Roueff et al. 2004, in prep.) to sulfur bearing species. SD, HDS, $\mathrm{D}_{2} \mathrm{~S}, \mathrm{HDCS}$ and $\mathrm{D}_{2} \mathrm{CS}, \mathrm{SD}^{+}, \mathrm{HDS}^{+}, \mathrm{D}_{2} \mathrm{~S}^{+}, \mathrm{H}_{2} \mathrm{DS}^{+}, \mathrm{HD}_{2} \mathrm{~S}^{+}, \mathrm{D}_{3} \mathrm{~S}^{+}, \mathrm{HDCS}^{+}, \mathrm{D}_{2} \mathrm{CS}^{+}, \mathrm{H}_{2} \mathrm{DCS}^{+}, \mathrm{HD}_{2} \mathrm{CS}^{+}$ and $\mathrm{D}_{3} \mathrm{CS}^{+}$have been added to the previous chemical network. We have assumed, as is usual in similar studies, that deuterated species behave as the main isotopic species and we have calculated the different branching ratios from statistical arguments except when dissociative recombination reactions were considered. In this latter case, we have assumed that removal of an hydrogen atom was more efficient that the release of $\mathrm{D}$ by a factor of 2 . This has indeed been seen in various experimental studies of multiply deuterated molecular ions as discussed by Le Petit \& Roueff (2003). The chemical reaction rate coefficients have been taken from our own chemical network (Pineau des Forêts et al. 1993), updated with the recent compilation of Anicich (2003) and from the available chemical network of the Ohio State University (Herbst and coworkers). As is recalled in Millar (2003), deuterium enrichment is initiated by the fractionation reactions of $\mathrm{H}_{3}^{+}, \mathrm{CH}_{3}^{+}$and $\mathrm{C}_{2} \mathrm{H}_{2}^{+}$with $\mathrm{D}$ and $\mathrm{HD}$. We have extended the reactions to the partially deuterated species until the fully deuterated ions $\mathrm{D}_{3}^{+}, \mathrm{CD}_{3}^{+}$and $\mathrm{C}_{2} \mathrm{D}_{2}^{+}$are formed -as studied in the laboratory by Gerlich \& Schlemmer (2002). Another important addition consists in considering the fractionation reactions with $\mathrm{D}_{2}$, which allows 
more substantial deuterium enhancement. Recent laboratory studies have shown that the reactions are significantly less efficient as currently assumed (cf. Millar 2003) and that the reverse endothermic reaction may be more rapid than expected from pure thermodynamics. We have thus taken the reaction rate coefficients derived from the experiments (Gerlich et al. 2002) but determined the reverse reactions with the calculated endothermicity. We have also introduced possible fractionation reactions of $\mathrm{H}_{2} \mathrm{CS}^{+}, \mathrm{H}_{3} \mathrm{CS}^{+}$and $\mathrm{H}_{3} \mathrm{~S}^{+}$with $\mathrm{HD}$, which could occur but have not been considered until now as no experimental or theoretical information is available. The corresponding reactions and rate coefficients are displayed in Table 8 where the values of the endothermicities involved in the backward reactions have been guessed. As the Langevin collision rates have been assumed, the results obtained by including these reactions will give upper limits for the deuterium fractionation.

Their influence is discussed below. We did not include the chemistry of methanol. The resulting chemical network consists in 210 species linked by more than 3000 chemical reactions. Details and discussion on the deuterated chemistry are discussed in Roueff et al. (2004, in prep.) and we focus the present discussion to the sulfur compound deuteration. Recent observations have shown that enhanced deuteration is linked to large depletions (see for example Bacmann et al. 2003). We consider then three different models with $\mathrm{H}_{2}$ densities of $10^{4}, 10^{5}$ and $10^{6}$ and different elemental depletions as displayed in Table 9 . These three models correspond approximately to the conditions found in TMC-1, Barnard 1 and L134N (see, Cernicharo \& Guélin 1987; Bachiller et al. 1990, Pagani et al. 2004, in press). The cosmic ionization rate and the temperature are kept constant and equal respectively to $2 \times 10^{-17} \mathrm{~s}^{-1}$ and $10 \mathrm{~K}$. The sulfur abundance is also taken constant and typical of the low metal case, i.e. $\mathrm{S} / \mathrm{H}_{2}=3.70 \times 10^{-7}$. The Table shows that, as expected, deuteration increases from models 1 to 3 . Fractionation reactions involving $\mathrm{H}_{2} \mathrm{CO}^{+}, \mathrm{H}_{3} \mathrm{CO}^{+}, \mathrm{H}_{3} \mathrm{~S}^{+}$and $\mathrm{H}_{3} \mathrm{CS}^{+}$, are seen to be of considerable importance for the fractionation of $\mathrm{H}_{2} \mathrm{~S}$. However, their role is much less for formaldehyde and thioformaldehyde. This is readily explained by the chemistry as hydrogen sulfide is directly obtained from dissociative recombination of $\mathrm{H}_{3} \mathrm{~S}^{+}$and involves a succession of ion molecule reactions. In the case of formaldehyde and thioformaldehyde, neutral reactions involving $\mathrm{CH}_{3}$ and atomic oxygen and atomic sulfur are supposed to occur at a rate of $1.4 \times 10^{-10}$. Then, deuterium enhancement of $\mathrm{H}_{2} \mathrm{CO}$ and $\mathrm{H}_{2} \mathrm{CS}$ reflects directly the deuterium enhancement of $\mathrm{CH}_{3}$. The reaction of $\mathrm{CH}_{3}$ and $\mathrm{O}$ has only been studied in the laboratory down to $300 \mathrm{~K}$ and the reaction rate coefficient with sulfur is taken from the chemical network of the Ohio State University in the group of E. Herbst.

As can be seen from the Table 9, this gas phase chemical model gives the correct orders of magnitude of the deuterium fractionation of ammonia, $\mathrm{HCO}^{+}, \mathrm{N}_{2} \mathrm{H}^{+}$for the high densities and large depletion factors when comparing to the observed values. In this model grains play a passive role, as they have trapped an important fraction of carbon and oxygen, allowing 
the gas phase chemical processes to proceed. We also give the fractional abundances of formaldehyde, sulfur hydride and thioformaldehyde to check the relevance of our gas phase chemical network. We note that the fractional abundance of sulfur hydride is between $10^{-9}$ and $4 \times 10^{-10}$ for the three models. This compares reasonably to the values found in TMC-1 and L134N as reported by Vastel et al. (2003). Grain surface chemistry is often invoked for the formation of $\mathrm{H}_{2} \mathrm{~S}$ as the $\mathrm{S}^{+}+\mathrm{H}_{2}$ reaction is highly endothermic. In the present chemical network, $\mathrm{SH}^{+}$is formed via $\mathrm{S}+\mathrm{H}_{3}^{+}$, which subsequently reacts with $\mathrm{H}_{2}$ via radiative association to produce $\mathrm{H}_{3} \mathrm{~S}^{+} \cdot \mathrm{H}_{2} \mathrm{~S}$ is then obtained from the dissociative recombination of $\mathrm{H}_{3} \mathrm{~S}^{+}$. The fractional abundance derived for $\mathrm{H}_{2} \mathrm{CS}$ is below the observed ones by values of a few. However, we have checked that increasing the elemental abundance of sulfur results in increasing the steady state fractional abundances of $\mathrm{H}_{2} \mathrm{~S}$ and $\mathrm{H}_{2} \mathrm{CS}$. We do not try to obtain a perfect fit with the observed values as many physical and chemical parameters are not well constrained. The present stage of agreement is nevertheless encouraging.

\section{CONCLUSIONS}

We have carried out a comprehensive observational study in Barnard 1 of the deuterated species of thioformaldehyde, together with the observation of several lines from the main isotope and from the ${ }^{34} \mathrm{~S}$ isotopic substituted species. In order to compare the deuterium enhancement we have also observed formaldehyde and its deuterated species. The main results are:

1) The systematic velocity of the dense gas in Barnard 1 has been determined to be $6.70 \pm 0.05 \mathrm{~km} \mathrm{~s}^{-1}$ from the observation of near 20 optically thin molecular lines with well known frequencies.

2) The observed frequencies for HDCS, $\mathrm{D}_{2} \mathrm{CS}$ and $\mathrm{H}_{2} \mathrm{C}^{34} \mathrm{~S}$ as well as the available laboratory data have been fit to obtain a set of molecular rotational constants allowing precise frequency determinations for these species in the millimeter domain.

3) Rotational temperatures and column densities for $\mathrm{H}_{2} \mathrm{CS}, \mathrm{H}_{2} \mathrm{CO}$ and their isotopes have been derived from rotational diagrams or through the use of a LVG code. The derived $\mathrm{H}_{2} \mathrm{CS} / \mathrm{HDCS}$ and $\mathrm{H}_{2} \mathrm{CS} / \mathrm{D}_{2} \mathrm{CS}$ abundance ratios are $\sim 3$ and 9 respectively, while for formaldehyde are $\sim 7$ and 13 .

4) Steady state gas phase chemical models including multiply deuterated species and with appropriate depletion factors, such as those found in different dense cores, allow to reproduce the deuterium fractionation approximately. In this context, surface processes have not to be included specifically, as they are poorly known, and their role is essentially 
passive as the abundant oxygen, $\mathrm{CO}, \mathrm{H}_{2} \mathrm{O}$... components are frozen on the grains and are not available for gas phase chemical processes to proceed. Our results involve also some specific chemical assumptions which contribute to the high deuterium fractionation, namely (1) specific branching ratios in dissociative recombination of deuterated molecular ions with a 1:2 ratio for the ejection of $\mathrm{H}$ compared to $\mathrm{D}$ as observed in several experiments. And (2) fractionation reactions of $\mathrm{H}_{2} \mathrm{CO}^{+}, \mathrm{H}_{3} \mathrm{CO}^{+}, \mathrm{H}_{3} \mathrm{~S}^{+}, \mathrm{H}_{2} \mathrm{CS}^{+}$with HD. These processes have not been studied in the laboratory nor theoretically and such studies would be very desirable. However, their influence on our results is not determinant except for the deuterium fractionation of $\mathrm{H}_{2} \mathrm{~S}$.

We would like to thank Spanish Ministry of Science and Technology, MCyT, for funding support under grants ANAYA2000-1784, ANAYA2003-2785 and PNIE2001-4516. The authors are also grateful for detailed reading and useful suggestions of the anonymous referee, which helped to improve this paper.

\section{REFERENCES}

Anicich, V. 2003, JPL publication 03-19

Bachiller, R. \& Cernicharo, J. 1984, A\&A, 140, 414

Bachiller, R., Menten, K.M. \& del Río-Alvarez, S. 1990, A\&A, 236, 461

Bacmann, A., Lefloch, B., Ceccarelli, C., Steinacker, J., Castets, A. \& Loinard, L. 2003, ApJ, 585, L55

Chu, F.Y., Freund, S.M., Johns, J.W.C. \& Oka, T., 1973, J. Mol. Spectrosc., 48, 328

Ceccarelli, C., Castets, A., Loinard, L., Caux, E. \& Tielens, A.G.G.M. 1998, A\&A, 338, L43

Ceccarelli, C., Vastel, C., Tielens, A.G.G.M., Castets, A., Boogert, A.C.A., Loinard, L. \& Caux, E. 2002, A\&A, 381, L17

Cernicharo, J., Bachiller, R. \& Duvert, G. 1984, A\&AS, 58, 327

Cernicharo, J. 1985, Internal report IRAM

Cernicharo, J. \& Guélin, M. 1987, A\&A, 176, 299

Cernicharo, J., Guélin, M. \& Kahane, C., 2000, A\&AS, 142, 181 
Charnley, S.B., Tielens, A.G.G.M. \& Rodgers, S.D. 1997, ApJ, 482, L203

Chin, Y.-N., Henkel, C., Whiteoak, J.B., Langer, N. \& Churchwell, E.B. 1996, A\&A, 305, 960

Clouthier, D.J. \& Ramsay, D.A. 1983, Ann. Rev. Phys. Chem., 34, 31

Cox, A.P., Hubbard, S.D. \& Kato, H. 1982, J. Mol. Spectrosc., 93, 196

Dangoisse, D., Villemot, E. \& Bellet, J. 1978, J. Mol. Spectrosc.,71 414

Frerking, M.A., Langer, W.D. \& Wilson, R.W. 1982, ApJ, 262, 590

Gerin, M., Pearson, J.C., Roueff, E., Falgarone, E. \& Phillips, T.G. 2001, ApJ, 551, L193

Gerlich, D., Herbst, E. \& Roueff, E. 2002, Planet. Space Sci., 50, 1275

Gerlich, D. \& Schlemmer, S. 2002, Planet. Space Sci., 50, 1287

Goldreich, P. \& Kwan, J. 1974, ApJ, 189, 441

Goldsmith, P.F. \& Langer, W.D. 1999, ApJ, 517, 209

Gordy, W. \& Cook, R.L. 1984, Microwave Molecular Spectra (New York: Wiley)

Green, S., Garrison, B.J. \& Lester, W.A. Jr. 1978, ApJS, 37, 321

Guélin, M., Langer, W.D. \& Wilson, R.W. 1982, A\&A, 107, 107

Hirano, N., Kameya, O., Mikami, H., Saito, S., Umemoto, T. \& Yamamoto, S. 1997, ApJ, 478,631

Hirano, N., Kamazaki, T., Mikami, H., Ohashi, N. \& Umemoto, T. 1999, Star Formation 1999, NRO, p 181

Langer, W.D., Goldsmith, P.F., Carlson, E.R. \& Wilson, R.W. 1980, ApJ, 235, L39

Le Petit, F. \& Roueff, E. 2003, in Dissociative Recombination of Molecular Ions with Electrons, ed. S. L. Guberman (New York: Kluwer Academic/Plenum Publishers), 373

Lis, D.C., Roueff, E., Gerin, M., Phillips, T.G., Coudert, L.H., van der Tak, F.F.S. \& Schilke, P. 2002, ApJ, 571, L55

Loinard, L., Castets, A., Ceccarelli, C., Tielens, A.G.G.M., Faure, A., Caux, E. \& Duvert, G. 2000, A\&A, 359, 1169 
Loinard, L., Castets, A., Ceccarelli, C., Caux, E. \& Tielens, A.G.G.M. 2001, ApJ, 552, L163

Lovas, F.J. 1992, J. Phys. Chem. Ref. Data, 21, 181

Matthews, B.C. \& Wilson, C.D. 2002, ApJ, 574, 822

Mauersberger, R., Henkel, C. \& Walmsley, C.M. 1988, A\&A, 194, L1

Millar, T.J. 2003, Space Sci. Rev., 106, 73

Minh, Y.C., Ziurys, L.M., Irvine, W.M. \& McGonagle, D. 1990, ApJ, 360, 136

Minowa, H., Satake, M., Hirota, T. \& Yamamoto, S. 1997, ApJ, 491, L63

McNaughton, D. \& Bruget, D.N. 1993, J. Mol. Spectrosc., 159, 340

Müller, H.S.P., Thorwirth, S., Roth, D.A. \& Winnewisser, G. 2001, A\&A, 370, L49

Pardo, J.R., Cernicharo, J. \& Serabyn, E. 2001, IEEE Transactions on antennas and propagation, 49, 12

Parise, B., Ceccarelli, C., Tielens, A.G.G.M., Herbst, E., Lefloch, B., Caux, E., Castets, A., Mukhopadhyay, I., Pagani, L. \& Loinard, L. 2002, A\&A, 393, L49

Parise, B., Castets, A., Herbst, E., Caux, E., Ceccarelli, C., Mukhopadhyay, I. \& Tielens, A.G.G.M. 2004, A\&A, 416, 159

Pickett, H.M., Poynter, R.L., Cohen, E.A., et al. 1998, J. Quant. Spec. Radiat. Transf., 60, 883

Pineau des Forêts, G., Roueff, E., Schilke, P. \& Flower, D.R. 1993, MNRAS, 262, 915

Roberts, H. \& Millar, T.J. 2000, A\&A, 364, 780

Roberts, H., Herbst, E. \& Millar, T.J. 2003, ApJ, 591, L41

Roueff, E., Tiné, S., Coudert, L.H., Pineau des Forêts, G., Falgarone, E. \& Gerin, M. 2000, A\&A, 354, L63

Saito, S., Ozeki, H., Ohishi, M. \& Yamamoto, S. 2000, ApJ, 535, 227

Tiné, S., Roueff, E., Falgarone, E., Gerin, M. \& Pineau des Forêts, G. 2000, A\&A, 356, 1039

Turner, B.E. \& Zuckerman, B. 1978, ApJ, 225, L75

Turner, P.H., Halonen, L. \& Mills, I.M., 1981, J. Mol. Spectrosc., 88, 402 
Turner, B.E. 1990, ApJ, 362, L29

Turner, B.E. 2001, ApJS, 136, 579

van Dishoeck, E.F., Blake, G.A., Jansen, D.J. \& Groesbeck, T.D. 1995, ApJ, 447, 760

Vastel, C., Phillips, T.G., Ceccarelli, C. \& Pearson, J. 2003, ApJ, 593, L97

Vastel, C., Phillips, T.G. \& Yoshida, H., 2004, ApJ, 606, L127

Watson, J.K.G. 1967, J. Chem. Phys., 46, 1935

Watson, J.K.G. 1977, Vibrational Spectra and Structure, Vol. 6, 1 (Elsevier, Amsterdam: J.R. Durig, Ed.)

Yamamoto, S., Mikami, H. \& Saito, S. 1992, PASJ, 44, 459

Yan, J., Wang, H., Wang, M., Deng, L., Yang, J. \& Chen, J. 1998, ApJ, 116, 2438 


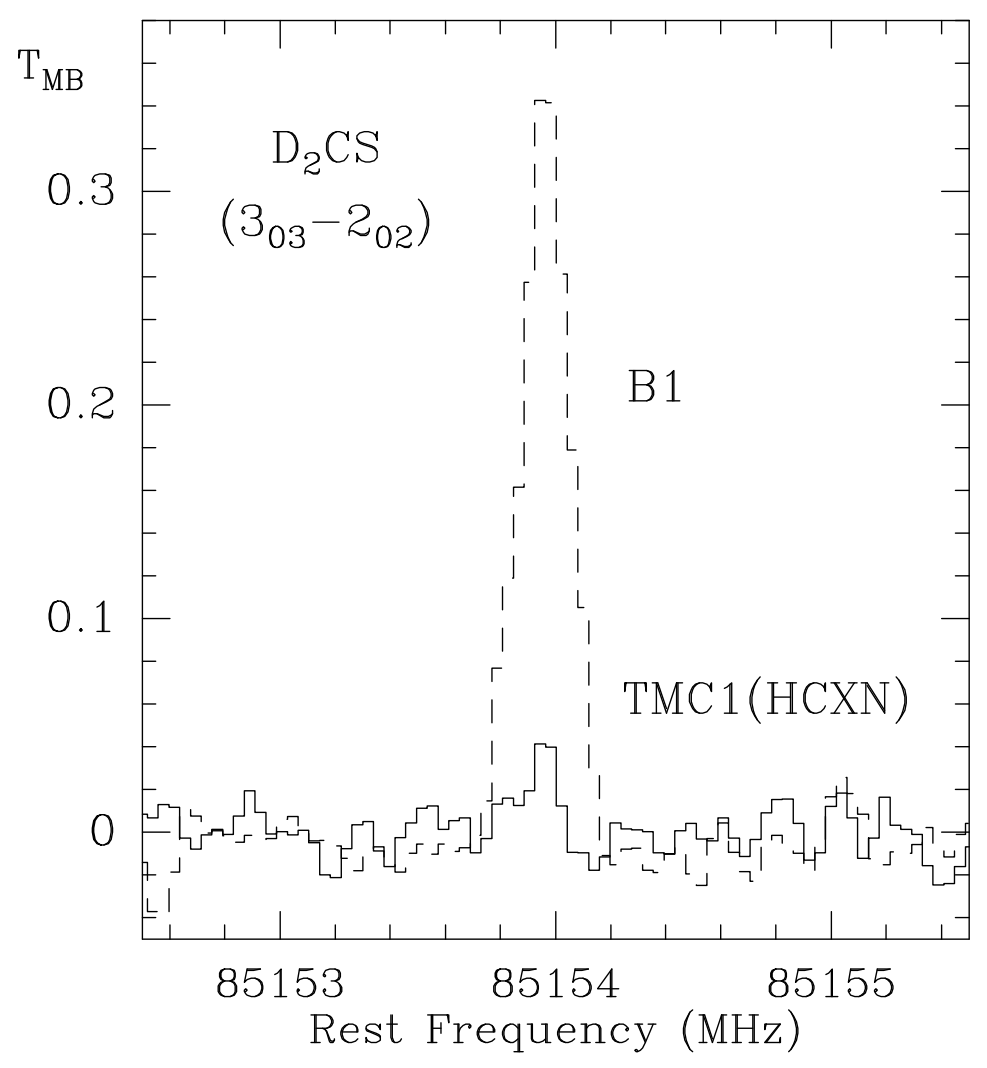

Fig. 1.- $\mathrm{D}_{2} \mathrm{CS}$ transition for Barnard 1 (dashed line) and for TMC-1 (solid line). The position of TMC- 1 is that of cyanopolyyne peak $\mathrm{RA}(1950.0)=04^{\mathrm{h}} 38^{\mathrm{m}} 38^{\mathrm{s}} \cdot 0, \operatorname{dec}(1950.0)=$ $+25^{\circ} 35^{\prime} 45^{\prime \prime}$; that of Barnard 1 is $\mathrm{RA}(2000.0)=03^{\mathrm{h}} 33^{\mathrm{m}} 20^{\mathrm{s}} .8, \operatorname{dec}(2000.0)=+31^{\circ} 07^{\prime} 34^{\prime \prime}$. 

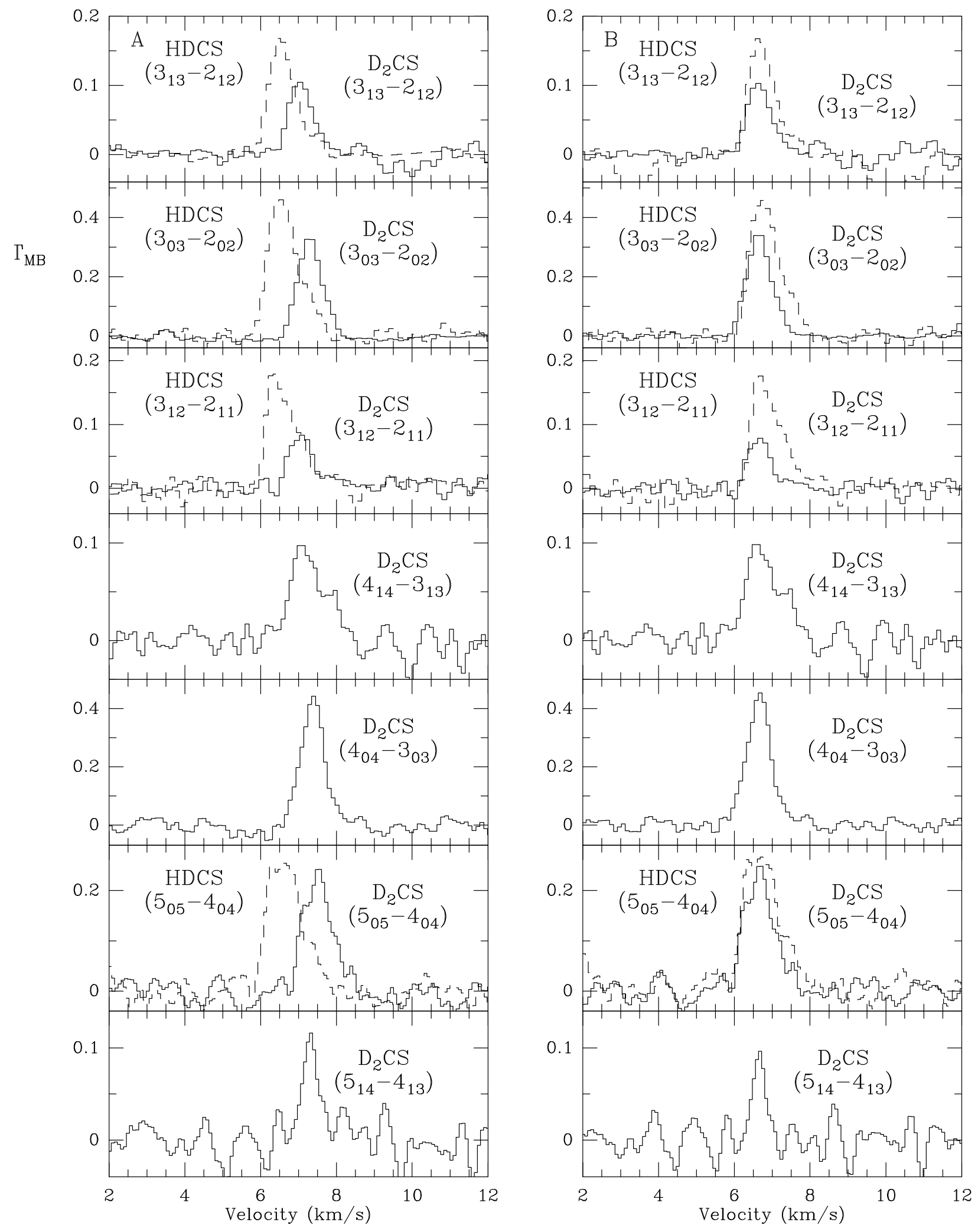

Fig. 2.- Observed transitions for HDCS (dashed line) and $\mathrm{D}_{2} \mathrm{CS}$ with the frequencies originally adopted from the literature (a) and the corrected frequencies (b). 


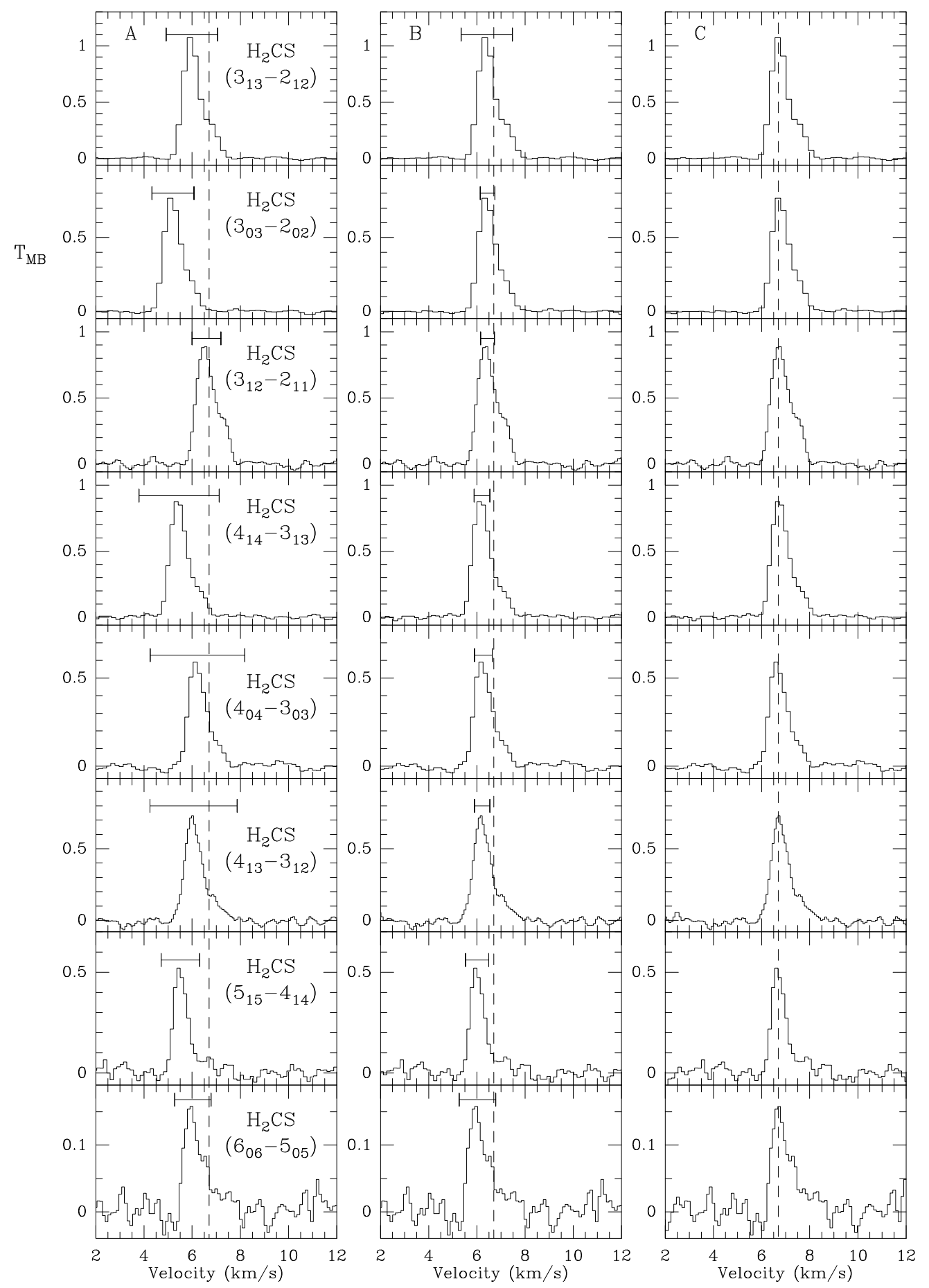

Fig. 3.- Observed transitions for $\mathrm{H}_{2} \mathrm{CS}$. The velocity scale in the left panels (A) has been derived from the laboratory frequencies, while for the central panels (B) the predicted frequencies from a fit to the laboratory data were used (see text). In the plots of these two columns the horizontal lines represent the $3 \sigma$ uncertainty for line frequencies (measured or predicted). Finally right panels $(\mathrm{C})$ show the $\mathrm{H}_{2} \mathrm{CS}$ lines when a velocity of $6.7 \mathrm{~km}^{-1}$ is assumed for the main velocity component. 


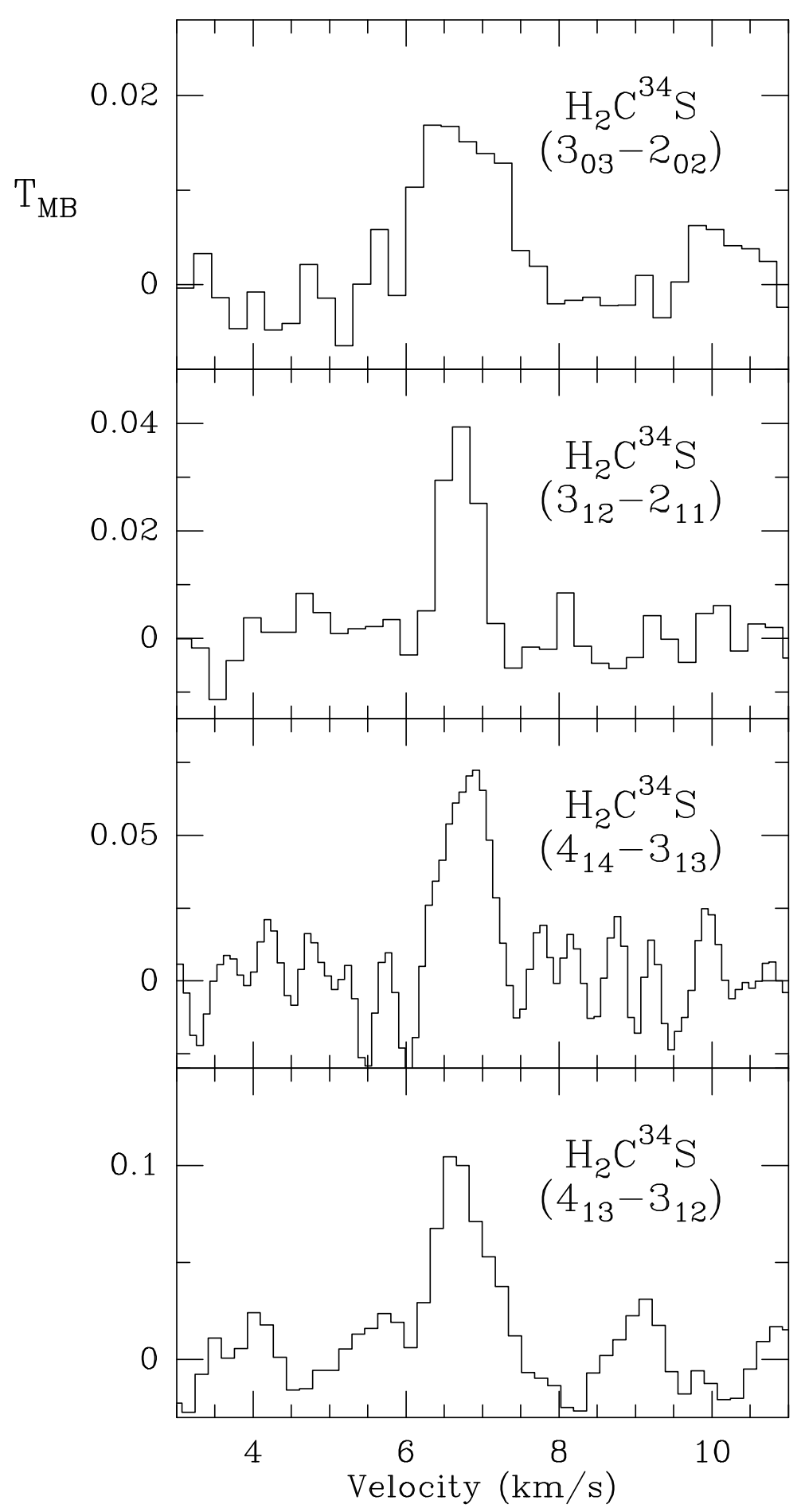

Fig. 4.- Observed transitions of $\mathrm{H}_{2} \mathrm{C}^{34} \mathrm{~S}$ in the direction of Barnard 1 . 


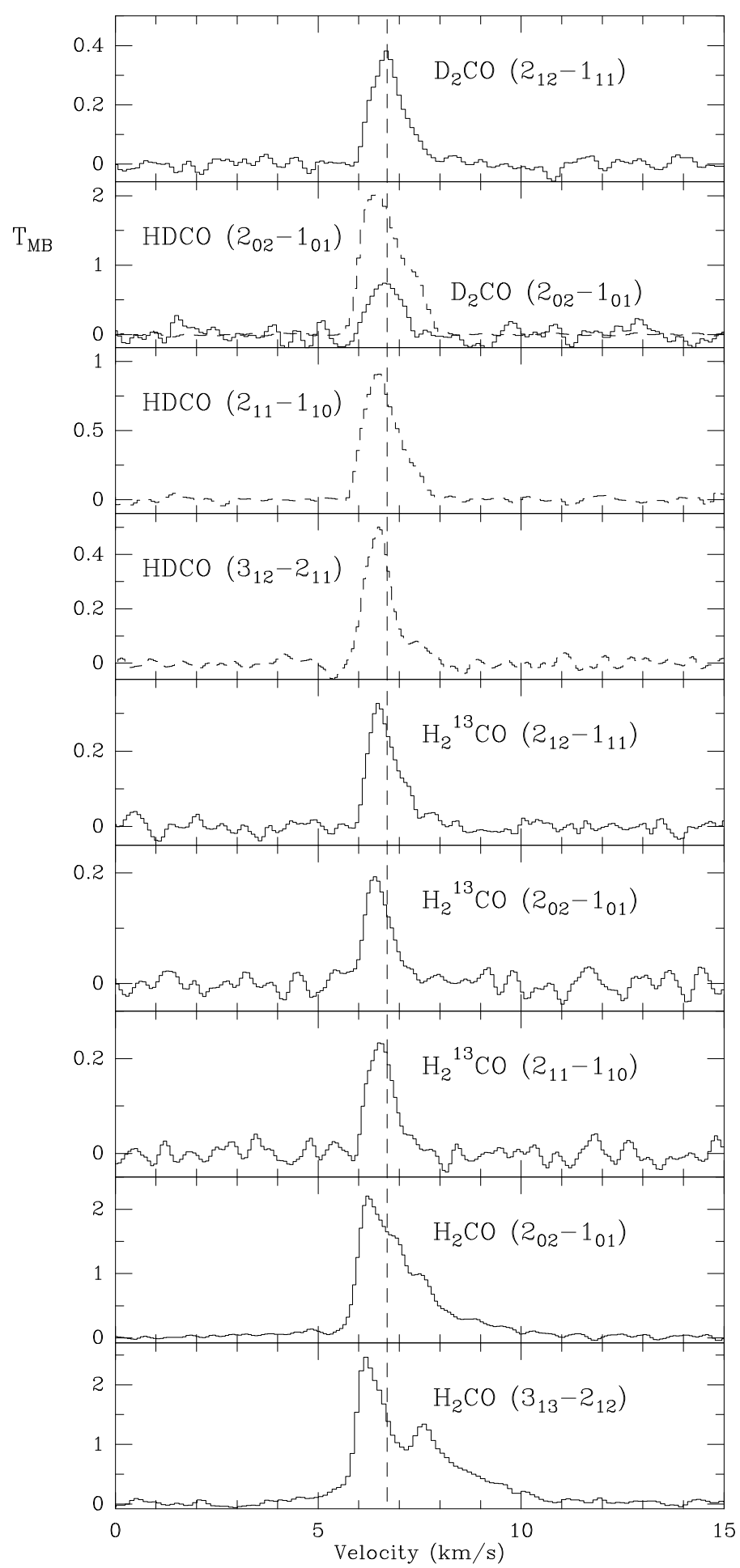

Fig. 5.- Observed transitions from the different isotopic species of formaldehyde. Velocity scale has been derived for the main isotope from the calculated frequencies for this species, while for the rare species the measured space frequency, assuming a velocity of $6.7 \mathrm{~km}^{-1}$, have been adopted (see text). 


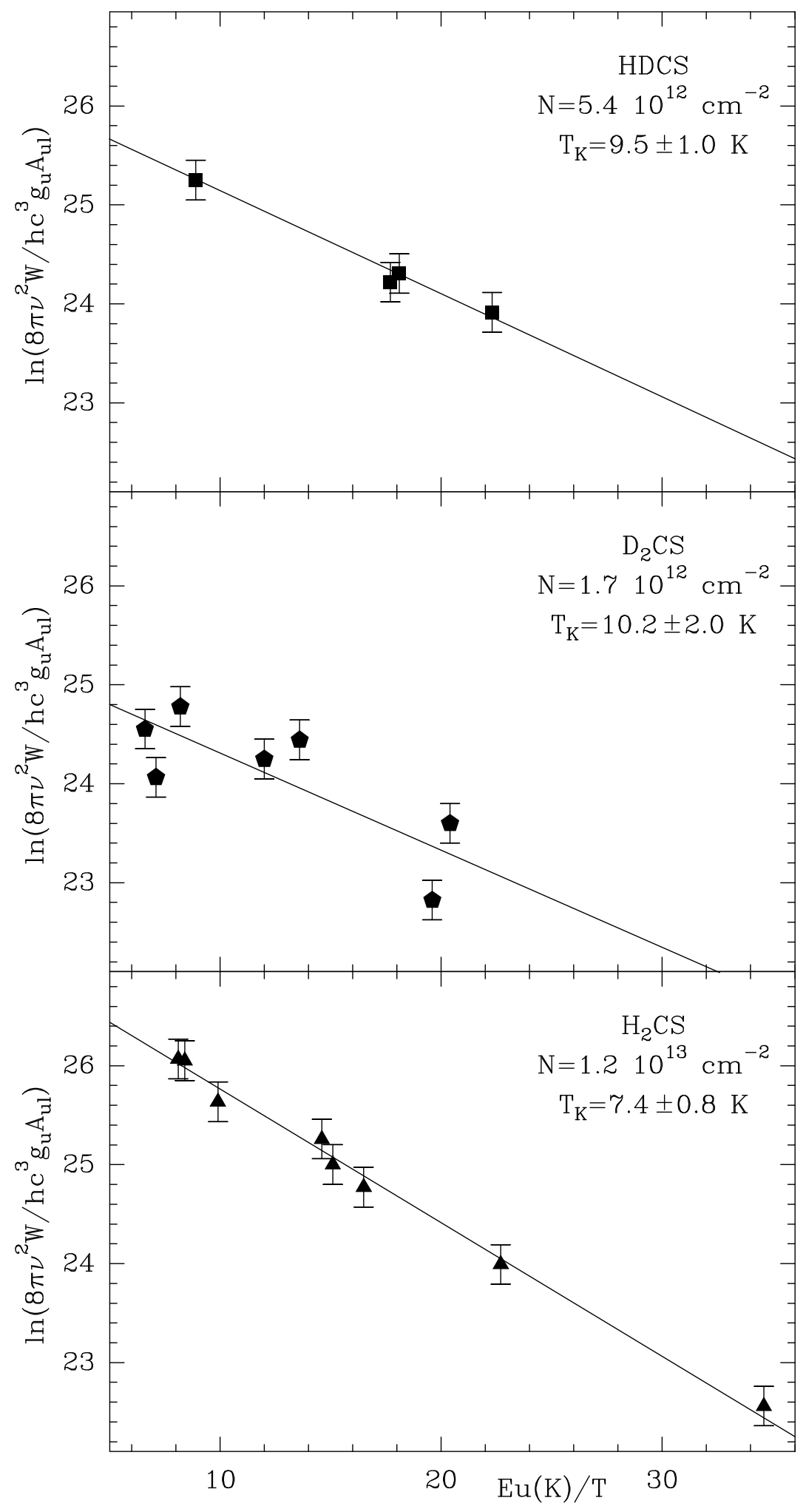

Fig. 6.- Rotational diagrams for $\mathrm{HDCS}, \mathrm{D}_{2} \mathrm{CS}$ and $\mathrm{H}_{2} \mathrm{CS}$. The errors are given between brackets and concerns the last significative digit. Column density values are the averaged ones. 
Table 1: Line parameters for the observed transitions of thioformaldehyde species

\begin{tabular}{cccccc}
\hline \hline Molecule & Transition & $\begin{array}{c}\text { Observed } \\
\text { Frequency } \\
(\mathrm{MHz})\end{array}$ & $\begin{array}{c}\text { Calculated } \\
\text { Frequency } \\
(\mathrm{MHz})\end{array}$ & $\begin{array}{c}T_{\mathrm{MB}} \\
(\mathrm{K})\end{array}$ & $\begin{array}{c}\Delta v \\
(\mathrm{~km} / \mathrm{s})\end{array}$ \\
\hline $\mathrm{HDCS}$ & $3_{13}-2_{12}$ & $91171.086(20)^{\mathrm{b}}$ & 91171.057 & $0.172(10)$ & 0.760 \\
& $3_{03}-2_{02}$ & $92981.658(30)$ & 92981.607 & $0.467(24)$ & 0.900 \\
& $3_{12}-2_{11}$ & $94828.592(41)$ & 94828.507 & $0.168(19)$ & 0.884 \\
& $5_{05}-4_{04}$ & $154885.070(40)$ & 154885.053 & $0.278(32)$ & 1.100 \\
$\mathrm{D}_{2} \mathrm{CS}$ & $3_{13}-2_{12}$ & $83077.759(24)$ & 83077.758 & $0.110(14)$ & 0.754 \\
& $3_{03}-2_{02}$ & $85153.920(12)$ & 85153.932 & $0.339(15)$ & 0.707 \\
& $3_{12}-2_{11}$ & $87302.662(24)$ & 87302.659 & $0.084(12)$ & 0.638 \\
& $4_{14}-3_{13}$ & $110756.126(60)$ & 110756.110 & $0.094(19)$ & 1.222 \\
& $4_{04}-3_{03}$ & $113484.714(12)$ & 113484.711 & $0.446(35)$ & 0.682 \\
& $5_{05}-4_{04}$ & $141769.445(60)$ & 141769.435 & $0.234(23)$ & 0.874 \\
$\mathrm{H}_{2} \mathrm{CS}$ & $5_{14}-4_{13}$ & $145461.965(20)$ & 145641.965 & $0.115(29)$ & 0.402 \\
& $3_{13}-2_{12}$ & $101477.879(6)$ & 101477.878 & $1.054(9)$ & 0.876 \\
& $3_{03}-2_{02}$ & $103040.539(12)$ & 103040.539 & $0.766(8)$ & 0.891 \\
& $3_{12}-2_{11}$ & $104617.114(15)$ & 104617.101 & $0.856(29)$ & 0.998 \\
& $4_{14}-3_{13}$ & $135298.407(15)$ & 135298.373 & $0.884(13)$ & 0.870 \\
& $4_{04}-3_{03}$ & $137371.268(12)$ & 137371.304 & $0.586(16)$ & 0.874 \\
& $4_{13}-3_{12}$ & $139483.741(24)$ & 139483.706 & $0.716(34)$ & 0.855 \\
& $5_{15}-4_{14}$ & $169114.198(30)$ & 169114.166 & $0.541(44)$ & 0.641 \\
& $6_{06}-5_{05}$ & $205987.954(60)$ & 205987.908 & $0.151(24)$ & 0.832 \\
$\mathrm{H}_{2} \mathrm{C}^{34} \mathrm{~S}$ & $3_{03}-2_{02}$ & $101284.331(80)$ & 101284.357 & $0.018(5)$ & 1.170 \\
& $3_{12}-2_{11}$ & $102807.426(40)$ & 102807.380 & $0.042(8)$ & 0.497 \\
& $4_{14}-3_{13}$ & $133027.035(40)$ & 133027.017 & $0.078(22)$ & 0.622 \\
& $4_{13}-3_{12}$ & $137071.099(30)$ & 137071.093 & $0.105(16)$ & 0.758
\end{tabular}

\footnotetext{
${ }^{a}$ Observed frequencies have been estimated from a Gaussian fit to the lines. Quoted frequencies correspond to the velocity component at $6.7 \mathrm{~km} \mathrm{~s}^{-1}$

${ }^{b}$ Errors for observed frequencies are given between brackets
} 
Table 2: Line parameters for the observed transitions of formaldehyde species

\begin{tabular}{|c|c|c|c|c|c|}
\hline Molecule & Transition & $\begin{array}{c}\text { Frequency } \\
(\mathrm{MHz})\end{array}$ & $\begin{array}{c}v_{L S R} \\
\left(\mathrm{~km} \mathrm{~s}^{-1}\right)^{\mathrm{b}}\end{array}$ & $\begin{array}{l}T_{\mathrm{MB}} \\
(\mathrm{K})\end{array}$ & $\begin{array}{c}\Delta v \\
\left(\mathrm{~km} \mathrm{~s}^{-1}\right)\end{array}$ \\
\hline \multirow[t]{6}{*}{$\mathrm{HDCO}$} & \multirow[t]{2}{*}{$2_{02}-1_{01}$} & \multirow[t]{2}{*}{128812.865} & 6.326 & $1.788(17)$ & 0.689 \\
\hline & & & 7.029 & 1.132 & 1.069 \\
\hline & \multirow[t]{2}{*}{$2_{11}-1_{10}$} & \multirow[t]{2}{*}{134284.909} & 6.389 & $0.781(19)$ & 0.681 \\
\hline & & & 6.962 & 0.374 & 1.017 \\
\hline & \multirow[t]{2}{*}{$3_{12}-2_{11}$} & \multirow[t]{2}{*}{201341.377} & 6.459 & $0.516(20)$ & 0.694 \\
\hline & & & 7.454 & 0.080 & 0.613 \\
\hline \multirow[t]{4}{*}{$\mathrm{D}_{2} \mathrm{CO}$} & \multirow[t]{3}{*}{$2_{12}-1_{11}$} & \multirow[t]{3}{*}{110837.821} & 6.272 & $0.164(20)$ & 0.345 \\
\hline & & & 6.698 & 0.354 & 0.567 \\
\hline & & & 7.265 & 0.107 & 0.731 \\
\hline & $2_{02}-1_{01}$ & 116688.442 & 6.658 & $0.817(121)$ & 0.839 \\
\hline \multirow[t]{8}{*}{$\mathrm{H}_{2} \mathrm{CO}$} & \multirow[t]{4}{*}{$2_{02^{-}} 1_{01}^{\mathrm{c}}$} & \multirow[t]{4}{*}{145602.949} & 6.244 & $2.217(42)$ & 0.590 \\
\hline & & & 6.860 & 1.340 & 0.563 \\
\hline & & & 7.513 & 0.722 & 0.795 \\
\hline & & & 8.483 & 0.264 & 2.264 \\
\hline & \multirow[t]{4}{*}{$3_{13}-2_{12}^{c}$} & \multirow[t]{4}{*}{211211.448} & 6.095 & $1.348(48)$ & 0.294 \\
\hline & & & 6.404 & 1.425 & 0.684 \\
\hline & & & 7.592 & 0.769 & 3.215 \\
\hline & & & 7.595 & 0.590 & 0.501 \\
\hline \multirow[t]{6}{*}{$\mathrm{H}_{2}{ }^{13} \mathrm{CO}$} & \multirow[t]{3}{*}{$2_{12^{-}} 1_{11}$} & \multirow[t]{3}{*}{137449.957} & 6.431 & $0.325(24)$ & 0.480 \\
\hline & & & 6.802 & 0.128 & 0.423 \\
\hline & & & 7.156 & 0.100 & 0.420 \\
\hline & $2_{02}-1_{01}$ & 141983.748 & 6.454 & $0.195(20)$ & 0.733 \\
\hline & \multirow[t]{2}{*}{$2_{11}-1_{10}$} & \multirow[t]{2}{*}{146635.672} & 6.527 & $0.249(22)$ & 0.681 \\
\hline & & & 7.315 & 0.040 & 0.206 \\
\hline
\end{tabular}

${ }^{a}$ Frequencies from Lovas catalog (see text)

${ }^{b}$ Different line components

${ }^{c}$ Complex line profiles with wings and selfabsorption 
Table 3: Rotational constants for $\mathrm{H}_{2} \mathrm{CS}$

\begin{tabular}{lcc}
\hline \hline Parameter & Laboratory & Lab+Sky \\
\hline $\mathrm{A}$ & $291718.6(133)$ & $291708.3(169)$ \\
$\mathrm{B}$ & $17699.6447(146)$ & $17699.6529(168)$ \\
$\mathrm{C}$ & $16651.8711(146)$ & $16651.8587(165)$ \\
$\Delta_{J}$ & $2.0638(391) \times 10^{-2}$ & $1.8916(178) \times 10^{-2}$ \\
$\Delta_{J K}$ & $5.20998(739) \times 10^{-1}$ & $5.22872(573) \times 10^{-1}$ \\
$\Delta_{K}$ & $22.8519^{\mathrm{a}}$ & $22.8519^{\mathrm{a}}$ \\
$\delta_{j}$ & $1.21460(129) \times 10^{-3}$ & $1.21438(163) \times 10^{-3}$ \\
$\delta_{k}$ & $3.1922(658) \times 10^{-1}$ & $3.2438(836) \times 10^{-1}$ \\
$\mathrm{H}_{J}$ & $1.056(492) \times 10^{-5}$ & $-8.41(313) \times 10^{-6}$ \\
&
\end{tabular}

${ }^{a}$ Value adopted from Clouthier \& Ramsay (1983) 
Table 4: Rotational constants for $\mathrm{D}_{2} \mathrm{CS}$

\begin{tabular}{lcc}
\hline \hline Parameter & Laboratory & Lab+Sky \\
\hline $\mathrm{A}$ & $146400.549(284)$ & $146397.685(725)$ \\
$\mathrm{B}$ & $14904.7104(116)$ & $14904.70899(556)$ \\
$\mathrm{C}$ & $13495.4298(116)$ & $13495.38776(506)$ \\
$\Delta_{J}$ & $1.2579^{\mathrm{a}} \times 10^{-2}$ & $1.29708(846) \times 10^{-2}$ \\
$\Delta_{J K}$ & $2.8869(166) \times 10^{-1}$ & $2.7972(178) \times 10^{-1}$ \\
$\Delta_{K}$ & $5.2084^{\mathrm{b}}$ & $6.588(294)$ \\
$\delta_{j}$ & $1.40587(269) \times 10^{-3}$ & $1.38673(369) \times 10^{-3}$ \\
$\delta_{k}$ & $2.14468(275) \times 10^{-1}$ & $2.2554(245) \times 10^{-1}$ \\
$\mathrm{H}_{J K}$ & $1.198(106) \times 10^{-6}$ & $7.25(125) \times 10^{-7}$ \\
$\mathrm{H}_{K J}$ & $-3.6562(919) \times 10^{-4}$ & $-3.075(151) \times 10^{-4}$ \\
& &
\end{tabular}

${ }^{a}$ Adopted value from Cox et al. (1982)

${ }^{b}$ Force field value (Turner et al. 1981) 
Table 5: Rotational constants of HDCS

\begin{tabular}{lcc}
\hline \hline Parameter & Laboratory & Lab+Sky \\
\hline $\mathrm{A}$ & $202716.66(217)$ & $202716.54(319)$ \\
$\mathrm{B}$ & $16111.38339(610)$ & $16111.38820(887)$ \\
$\mathrm{C}$ & $14890.97584(603)$ & $14890.97943(867)$ \\
$\Delta_{J}$ & $1.587381(547) \times 10^{-2}$ & $1.588513(787) \times 10^{-2}$ \\
$\Delta_{J K}$ & $3.180421(533) \times 10^{-1}$ & $3.181521(768) \times 10^{-1}$ \\
$\Delta_{K}$ & $14.72^{\mathrm{a}}$ & $14.72^{\mathrm{a}}$ \\
$\delta_{j}$ & $1.38002(484) \times 10^{-3}$ & $1.37782(621) \times 10^{-3}$ \\
$\delta_{k}$ & $2.8831(281) \times 10^{-1}$ & $2.8839(414) \times 10^{-1}$ \\
$\mathrm{H}_{J K}$ & $2.028(217) \times 10^{-6}$ & $2.476(312) \times 10^{-6}$ \\
$\mathrm{H}_{K J}$ & $-4.188(109) \times 10^{-5}$ & $-4.193(160) \times 10^{-5}$ \\
&
\end{tabular}

${ }^{a}$ Interpolated value from $\mathrm{H}_{2} \mathrm{CS}$ and $\mathrm{D}_{2} \mathrm{CS}$ 
Table 6: Rotational constants of $\mathrm{H}_{2} \mathrm{C}^{34} \mathrm{~S}$

\begin{tabular}{lcc}
\hline \hline Parameter & Laboratory & Lab+Sky \\
\hline $\mathrm{A}$ & $291708.3^{\mathrm{a}}$ & $291708.3^{\mathrm{a}}$ \\
$\mathrm{B}$ & $17389.1451(120)$ & $17389.1477(108)$ \\
$\mathrm{C}$ & $16376.6721(120)$ & $16376.6745(108)$ \\
$\Delta_{J}$ & $1.8417(486) \times 10^{-2}$ & $1.8283(399) \times 10^{-2}$ \\
$\Delta_{J K}$ & $5.0236(169) \times 10^{-1}$ & $5.0328(138) \times 10^{-1}$ \\
$\Delta_{K}$ & $22.8519^{\mathrm{a}}$ & $22.8519^{\mathrm{a}}$ \\
$\delta_{j}$ & $1.1662(158) \times 10^{-3}$ & $1.1673(151) \times 10^{-3}$ \\
$\delta_{k}$ & $3.2438^{\mathrm{a}} \times 10^{-1}$ & $3.2438^{\mathrm{a}} \times 10^{-1}$
\end{tabular}

${ }^{a}$ Fixed to the value of $\mathrm{H}_{2} \mathrm{CS}$ 
Table 7: Relative abundances of deuterated molecules in several sources

\begin{tabular}{lrrrrrr}
\hline \hline Molecule & Barnard 1 & TMC- $^{a}$ & TMC- $^{b}$ & L134N & IRAS 16293-2422 & Orion (KL) \\
\hline $\mathrm{DCO}^{+} / \mathrm{HCO}^{+}$ & & $0.012^{1}$ & & $0.180^{2}$ & $0.009^{3}$ & $<0.01^{4}$ \\
$\mathrm{~N}_{2} \mathrm{D}^{+} / \mathrm{N}_{2} \mathrm{H}^{+}$ & $0.150^{5}$ & $0.0064^{1}$ & $0.080^{2}$ & $0.300^{5}$ & & $<0.30^{4}$ \\
$\mathrm{NH}_{2} \mathrm{D} / \mathrm{NH}_{3}$ & $0.128^{6}$ & $<0.001^{1}$ & $0.020^{2}$ & $0.10^{2,7}$ & $0.100^{3}$ & $0.062^{8}$ \\
$\mathrm{ND}_{2} \mathrm{H} / \mathrm{NH}_{2} \mathrm{D}$ & & & & $0.050^{7}$ & & \\
$\mathrm{ND}_{3} / \mathrm{NH}_{3}$ & $0.0008^{9}$ & & & & & \\
\hline $\mathrm{HDCO} / \mathrm{H}_{2} \mathrm{CO}$ & 0.143 & & $0.059^{1}$ & $0.068^{1}$ & $0.140^{3}$ & $0.140^{8}$ \\
$\mathrm{D}_{2} \mathrm{CO} / \mathrm{HDCO}$ & 0.400 & & & & $<0.50^{7}$ & $0.021^{8}$ \\
$\mathrm{HDS} / \mathrm{H}_{2} \mathrm{~S}$ & & & & & $0.100^{3}$ & $<0.02^{11}$ \\
$\mathrm{D}_{2} \mathrm{~S} / \mathrm{HDS}$ & $0.108^{12}$ & & & & $<0.264^{12}$ & \\
$\mathrm{HDCS} / \mathrm{H}_{2} \mathrm{CS}$ & 0.300 & $0.020^{13}$ & & & & \\
$\mathrm{D}_{2} \mathrm{CS} / \mathrm{HDCS}$ & 0.333 & & & & & \\
\hline $\mathrm{CH}_{3} \mathrm{OD} / \mathrm{CH}_{3} \mathrm{OH}$ & & $0.026^{1}$ & & $<0.032^{1}$ & $0.015^{14}$ & $0.01-0.06^{15}$ \\
$\mathrm{CH}_{2} \mathrm{DOH} / \mathrm{CH} \mathrm{H}_{3} \mathrm{OH}$ & & & & & $0.306^{14}$ & \\
$\mathrm{CHD}_{2} \mathrm{OH} / \mathrm{CH}{ }_{3} \mathrm{OH}$ & & & & & $0.060^{14}$ & \\
$\mathrm{CD}_{3} \mathrm{OH} / \mathrm{CH}_{3} \mathrm{OH}$ & & & & & $\sim 0.010^{14}$ &
\end{tabular}

${ }^{a}$ Cyanopolyyne peak

${ }^{b}$ Ammonia peak

References. - 1. Turner (2001); 2. Tiné et al. (2000); 3. van Dishoeck et al. (1995); 4. Turner \& Zuckerman (1978); 5. Gerin et al. (2001); 6. Saito et al. (2000); 7. Roueff et al. (2000); 8. Turner (1990); 9. Lis et al. (2002); 10. Loinard et al. (2000); 11. Minh et al. (1990); 12. Vastel et al. (2003); 13. Minowa et al. (1997); 14. Parise et al. (2004); 15. Mauersberger et al. (1988). 
Table 8: Fractionation reactions introduced in the network

\begin{tabular}{|c|c|c|}
\hline Reaction & $\begin{array}{c}\mathrm{k}_{f}^{\mathrm{a}} \\
\left(\mathrm{cm}^{3} \mathrm{~s}^{-1}\right)\end{array}$ & $\begin{array}{c}\beta \\
(\mathrm{K})\end{array}$ \\
\hline $\mathrm{H}_{3} \mathrm{CO}^{+}+\mathrm{HD} \rightleftharpoons \mathrm{H}_{2} \mathrm{DCO}^{+}+\mathrm{H}_{2}$ & $2.0 \times 10^{-9}$ & 500 \\
\hline $\mathrm{H}_{3} \mathrm{~S}^{+}+\mathrm{HD} \rightleftharpoons \mathrm{H}_{2} \mathrm{DS}^{+}+\mathrm{H}_{2}$ & $2.0 \times 10^{-9}$ & 500 \\
\hline $\mathrm{H}_{2} \mathrm{DS}^{+}+\mathrm{HD} \rightleftharpoons \mathrm{HD}_{2} \mathrm{~S}^{+}+\mathrm{H}_{2}$ & $2.0 \times 10^{-9}$ & 400 \\
\hline $\mathrm{HD}_{2} \mathrm{~S}^{+}+\mathrm{HD} \rightleftharpoons \mathrm{D}_{3} \mathrm{~S}^{+}+\mathrm{H}_{2}$ & $2.0 \times 10^{-9}$ & 300 \\
\hline $\mathrm{H}_{3} \mathrm{~S}^{+}+\mathrm{D}_{2} \rightleftharpoons \mathrm{HD}_{2} \mathrm{~S}^{+}+\mathrm{H}_{2}$ & $2.0 \times 10^{-9}$ & 500 \\
\hline $\mathrm{H}_{2} \mathrm{DS}^{+}+\mathrm{D}_{2} \rightleftharpoons \mathrm{D}_{3} \mathrm{~S}^{+}+\mathrm{H}_{2}$ & $2.0 \times 10$ & 400 \\
\hline $\mathrm{H}_{2} \mathrm{DS}^{+} \mathrm{D}_{2} \rightarrow \mathrm{HD}_{2} \mathrm{~S}^{+}+\mathrm{HD}$ & $2.0 \times 10$ & 400 \\
\hline $\mathrm{HD}_{2} \mathrm{~S}^{+}+\mathrm{D}_{2} \rightleftharpoons \mathrm{D}_{3} \mathrm{~S}^{+}+\mathrm{HD}$ & $2.0 \times 10^{-9}$ & 300 \\
\hline $\mathrm{H}_{2} \mathrm{CS}^{+}+\mathrm{HD} \rightleftharpoons \mathrm{HDCS}^{+} \mathrm{H}_{2}$ & $2.0 \times 10^{-9}$ & 500 \\
\hline $\mathrm{HDCS}^{+}+\mathrm{HD} \rightleftharpoons \mathrm{D}_{2} \mathrm{CS}^{+} \mathrm{H}_{2}$ & $2.0 \times 10^{-9}$ & 400 \\
\hline $\mathrm{H}_{2} \mathrm{CS}^{+}+\mathrm{D}_{2} \rightleftharpoons \mathrm{D}_{2} \mathrm{CS}^{+} \mathrm{H}_{2}$ & $2.0 \times 10^{-9}$ & 500 \\
\hline $\mathrm{H}_{2} \mathrm{CS}^{+}+\mathrm{D}_{2} \rightleftharpoons \mathrm{HDCS}^{+} \mathrm{HD}$ & $2.0 \times 10^{-9}$ & 400 \\
\hline $\mathrm{HDCS}^{+}+\mathrm{D}_{2} \rightleftharpoons \mathrm{D}_{2} \mathrm{CS}^{+} \mathrm{HD}$ & $2.0 \times 10^{-9}$ & 300 \\
\hline $\mathrm{H}_{3} \mathrm{CS}^{+}+\mathrm{HD} \rightleftharpoons \mathrm{H}_{2} \mathrm{DCS}^{+} \mathrm{H}_{2}$ & $2.0 \times 10^{-9}$ & 500 \\
\hline $\mathrm{H}_{2} \mathrm{DCS}^{+}+\mathrm{HD} \rightleftharpoons \mathrm{HD}_{2} \mathrm{CS}^{+} \mathrm{H}_{2}$ & $2.0 \times 10^{-9}$ & 400 \\
\hline $\mathrm{HD}_{2} \mathrm{CS}^{+}+\mathrm{HD} \rightleftharpoons \mathrm{D}_{3} \mathrm{CS}^{+} \mathrm{H}_{2}$ & $2.0 \times 10^{-9}$ & 400 \\
\hline $\mathrm{H}_{3} \mathrm{CS}^{+}+\mathrm{D}_{2} \rightleftharpoons \mathrm{HD}_{2} \mathrm{CS}^{+} \mathrm{H}_{2}$ & $2.0 \times 10^{-9}$ & 500 \\
\hline $\mathrm{H}_{3} \mathrm{CS}^{+}+\mathrm{D}_{2} \rightleftharpoons \mathrm{H}_{2} \mathrm{DCS}^{+} \mathrm{H}_{2}$ & $2.0 \times 10^{-9}$ & 400 \\
\hline $\mathrm{H}_{2} \mathrm{DCS}^{+}+\mathrm{D}_{2} \rightleftharpoons \mathrm{HD}_{2} \mathrm{CS}^{+} \mathrm{HD}$ & $2.0 \times 10^{-9}$ & 500 \\
\hline $\mathrm{HD}_{2} \mathrm{CS}^{+}+\mathrm{D}_{2} \rightleftharpoons \mathrm{D}_{3} \mathrm{CS}^{+} \mathrm{HD}$ & $2.0 \times 10^{-9}$ & 500 \\
\hline $\mathrm{H}_{3} \mathrm{~S}^{+}+\mathrm{D} \rightleftharpoons \mathrm{H}_{2} \mathrm{DS}^{+}+\mathrm{H}$ & $2.0 \times 10^{-9}$ & 500 \\
\hline $\mathrm{H}_{2} \mathrm{DS}^{+}+\mathrm{D} \rightleftharpoons \mathrm{HD}_{2} \mathrm{~S}^{+}+\mathrm{H}$ & $2.0 \times 10^{-9}$ & 400 \\
\hline $\mathrm{HD}_{2} \mathrm{~S}^{+}+\mathrm{D} \rightleftharpoons \mathrm{D}_{3} \mathrm{~S}^{+}+\mathrm{H}$ & $2.0 \times 10^{-9}$ & 300 \\
\hline $\mathrm{H}_{2} \mathrm{CS}^{+}+\mathrm{D} \rightleftharpoons \mathrm{HDCS}^{+}+\mathrm{H}$ & $2.0 \times 10^{-9}$ & 500 \\
\hline $\mathrm{HDCS}^{+}+\mathrm{D} \rightleftharpoons \mathrm{D}_{2} \mathrm{CS}^{+}+\mathrm{H}$ & $2.0 \times 10^{-9}$ & 400 \\
\hline $\mathrm{H}_{3} \mathrm{CS}^{+}+\mathrm{D} \rightleftharpoons \mathrm{H}_{2} \mathrm{DCS}^{+}+\mathrm{H}$ & $2.0 \times 10^{-9}$ & 500 \\
\hline $\mathrm{H}_{2} \mathrm{DCS}^{+}+\mathrm{D} \rightleftharpoons \mathrm{HD}_{2} \mathrm{CS}^{+}+\mathrm{H}$ & $2.0 \times 10^{-9}$ & 400 \\
\hline $\mathrm{HD}_{2} \mathrm{CS}^{+}+\mathrm{D} \rightleftharpoons \mathrm{D}_{3} \mathrm{CS}^{+}+\mathrm{H}$ & $2.0 \times 10^{-9}$ & 300 \\
\hline
\end{tabular}

${ }^{a}$ The forward rate is $\mathrm{k}_{f}$; the reverse rate, $\mathrm{k}_{r}$, is given by $\mathrm{k}_{f} \mathrm{e}^{-\beta / T}$ 
Table 9: Prediction of sulfur containing molecules fractional abundances and deuterium fractionation.

\begin{tabular}{|c|c|c|c|}
\hline model conditions & Model 1 & Model 2 & Model 3 \\
\hline $\mathrm{H}_{2}\left(\mathrm{~cm}^{-3}\right)$ & $10^{4}$ & $10^{5}$ & $10^{6}$ \\
\hline $\mathrm{C} / \mathrm{H}_{2}$ & $7.5 \times 10^{-5}$ & $3.0 \times 10^{-5}$ & $1.5 \times 10^{-5}$ \\
\hline $\mathrm{O} / \mathrm{H}_{2}$ & $2 \times 10^{-4}$ & $8 \times 10^{-5}$ & $4 \times 10^{-5}$ \\
\hline $\mathrm{N} / \mathrm{H}_{2}$ & $2 \times 10^{-5}$ & $2 \times 10^{-5}$ & $2 \times 10^{-5}$ \\
\hline representative molecular cloud & TMC-1 & Barnard 1 & L134N \\
\hline \multicolumn{4}{|l|}{ steady state results } \\
\hline $\mathrm{H}\left(\mathrm{cm}^{-3}\right)$ & 2.24 & 2.22 & 2.25 \\
\hline $\mathrm{HD}\left(\mathrm{cm}^{-3}\right)$ & $2.76 \times 10^{-1}$ & 2.76 & 26.8 \\
\hline $\mathrm{x}\left(\mathrm{e}^{-}\right)^{a}$ & $6.03 \times 10^{-8}$ & $3.52 \times 10^{-8}$ & $2.60 \times 10^{-8}$ \\
\hline \multirow[t]{2}{*}{$\mathrm{x}\left(\mathrm{H}_{2} \mathrm{CO}\right)^{b}$} & $1.2 \times 10^{-9}$ & $4.7 \times 10^{-10}$ & $1.1 \times 10^{-10}$ \\
\hline & $1.3 \times 10^{-9}$ & $5.0 \times 10^{-10}$ & $1.1 \times 10^{-10}$ \\
\hline \multirow[t]{2}{*}{$\mathrm{x}\left(\mathrm{H}_{2} \mathrm{~S}\right)^{b}$} & $4.5 \times 10^{-10}$ & $8.1 \times 10^{-10}$ & $8.7 \times 10^{-10}$ \\
\hline & $6.1 \times 10^{-10}$ & $1.4 \times 10^{-9}$ & $1.7 \times 10^{-9}$ \\
\hline \multirow[t]{2}{*}{$\mathrm{x}\left(\mathrm{H}_{2} \mathrm{CS}\right)^{b}$} & $4.1 \times 10^{-11}$ & $2.9 \times 10^{-11}$ & $1.0 \times 10^{-11}$ \\
\hline & $4.8 \times 10^{-11}$ & $2.9 \times 10^{-11}$ & $1.3 \times 10^{-11}$ \\
\hline $\mathrm{D} / \mathrm{H}$ & 0.0053 & 0.012 & 0.021 \\
\hline $\mathrm{D}_{2} / \mathrm{HD}$ & 0.021 & 0.036 & 0.059 \\
\hline $\mathrm{H}_{2} \mathrm{D}^{+} / \mathrm{H}_{3}+$ & 0.029 & 0.10 & 0.16 \\
\hline $\mathrm{D}_{2} \mathrm{H}^{+} / \mathrm{H}_{2} \mathrm{D}^{+}$ & 0.054 & 0.10 & 0.16 \\
\hline $\mathrm{D}_{3}^{+} / \mathrm{D}_{2} \mathrm{H}^{+}$ & 0.041 & 0.086 & 0.15 \\
\hline \multirow[t]{2}{*}{$\mathrm{HDCO} / \mathrm{H}_{2} \mathrm{CO}^{b}$} & 0.091 & 0.12 & 0.14 \\
\hline & 0.048 & 0.07 & 0.089 \\
\hline \multirow[t]{2}{*}{$\mathrm{D}_{2} \mathrm{CO} / \mathrm{HDCO}^{b}$} & 0.34 & 0.57 & 0.80 \\
\hline & 0.60 & 0.95 & 1.20 \\
\hline \multirow[t]{2}{*}{$\mathrm{HDS} / \mathrm{H}_{2} \mathrm{~S}^{b}$} & 0.26 & 0.37 & 0.43 \\
\hline & 0.017 & 0.032 & 0.050 \\
\hline \multirow[t]{2}{*}{$\mathrm{D}_{2} \mathrm{~S} / \mathrm{HDS}^{b}$} & 0.53 & 1.0 & 1.32 \\
\hline & 0.0049 & 0.007 & 0.0086 \\
\hline \multirow[t]{2}{*}{$\mathrm{HDCS} / \mathrm{H}_{2} \mathrm{CS}^{b}$} & 0.16 & 0.18 & 0.18 \\
\hline & 0.041 & 0.065 & 0.086 \\
\hline \multirow[t]{2}{*}{$\mathrm{D}_{2} \mathrm{CS} / \mathrm{HDCS}^{b}$} & 0.48 & 0.85 & 1.17 \\
\hline & 0.37 & 0.67 & 0.92 \\
\hline $\mathrm{DCO}^{+} / \mathrm{HCO}^{+}$ & 0.028 & 0.043 & 0.066 \\
\hline $\mathrm{NH}_{2} \mathrm{D} / \mathrm{NH}_{3}$ & 0.040 & 0.077 & 0.20 \\
\hline $\mathrm{ND}_{2} \mathrm{H} / \mathrm{NH}_{2} \mathrm{D}$ & 0.027 & 0.041 & 0.051 \\
\hline $\mathrm{ND}_{3} / \mathrm{ND}_{2} \mathrm{H}$ & 0.035 & 0.05 & 0.056 \\
\hline $\mathrm{N}_{2} \mathrm{D}^{+} / \mathrm{N}_{2} \mathrm{H}^{+}$ & 0.032 & 0.047 & 0.068 \\
\hline
\end{tabular}

